Article

\title{
Assessing Fluorescent Organic Matter in Natural Waters: Towards In Situ Excitation-Emission Matrix Spectroscopy
}

\author{
Oliver Zielinski ${ }^{1, * \mathbb{D}}$, Nick Rüssmeier ${ }^{1,2}$, Oliver D. Ferdinand ${ }^{1}$, Mario L. Miranda ${ }^{1,3}$ \\ and Jochen Wollschläger ${ }^{1,4}$ \\ 1 Center for Marine Sensors, Institute for Chemistry and Biology of the Marine Environment, University \\ Oldenburg, 26382 Wilhelmshaven, Germany; nick.ruessmeier@uol.de (N.R.); oliver.ferdinand@uol.de (O.D.F.); \\ mario.luis.miranda.montenegro@uol.de (M.L.M.); jochen.wollschlaeger@uol.de (J.W.) \\ 2 OFFIS e.V. Institute for Information Technology, 26121 Oldenburg, Germany \\ 3 Laboratory of Air and Water Quality, University of Panama, Panamá 4, Panamá \\ 4 Helmholtz-Zentrum Geesthacht, Institute of Coastal Research, Max-Planck-Str. 1, 21502 Geesthacht \\ * Correspondence: oliver.zielinski@uol.de; Tel.: +49-441-798-3518
}

Received: 12 July 2018; Accepted: 26 November 2018; Published: 19 December 2018

Featured Application: This proof-of-concept work of in situ EEMS might find applications on different autonomous platforms in biogeochemical observing systems for the marine environment.

\begin{abstract}
Natural organic matter (NOM) is a key parameter in aquatic biogeochemical processes. Part of the NOM pool exhibits optical properties, namely absorption and fluorescence. The latter is frequently utilized in laboratory measurements of its dissolved fraction (fluorescent dissolved organic matter, FDOM) through excitation-emission matrix spectroscopy (EEMS). We present the design and field application of a novel EEMS sensor system applicable in situ, the 'Kallemeter'. Observations are based on a field campaign, starting in Norwegian coastal waters entering the Trondheimsfjord. Comparison against the bulk fluorescence of two commercial FDOM sensors exhibited a good correspondence of the different methods and the ability to resolve gradients and dynamics along the transect. Complementary laboratory EEM spectra measurements of surface water samples and their subsequent PARAFAC analysis revealed three dominant components while the 'Kallemeter' EEMS sensor system was able to produce reasonable EEM spectra in high DOM concentrated water bodies, yet high noise levels must be addressed in order to provide comparable PARAFAC components. Achievements and limitations of this proof-of-concept are discussed providing guidance towards full in situ EEMS measurements to resolve rapid changes and processes in natural waters based on the assessment of spectral properties. Their combination with multiwavelength FDOM sensors onboard autonomous platforms will enhance our capacities in observing biogeochemical processes in the marine environment in spatiotemporal and spectral dimensions.
\end{abstract}

Keywords: natural organic matter; DOM; FDOM; CDOM; Gelbstoff; EEMS; PARAFAC; marine sensors; Kallemeter; FerryBox; Trondheimsfjord; Norway

\section{Introduction}

The investigation of natural organic matter (NOM) and especially its dissolved fraction (DOM) is of high relevance in aquatic sciences. Studies of NOM and DOM include their sinks and sources as part of the global carbon cycle [1-4], its stability and degradability by abiotic and biotic processes [5,6], as well as natural and anthropogenic ecosystem effects e.g., from hydrocarbons [7]. Complementary to laboratory approaches, the need to measure DOM directly in the water column 
(in situ) initiated the development of field-applicable optical sensors that can be attached to autonomous vehicles or ship-based platforms [8]. Addressing the optical properties, namely absorption and fluorescence, of certain DOM fractions in situ sensors enable a high-resolution assessment of these ecosystem-relevant parameters or proxies on different observation platforms $[9,10]$. The absorption of light from fractions of the DOM pool is a long known feature, which was initially investigated by the German chemist Kurt Kalle in the early 20th century [11]. Observing an increased absorption of light towards the blue and ultraviolet (UV) part of the spectrum, he denoted this fraction of DOM as 'Gelbstoff' or 'yellow substance' [12,13], apparently inspired by the yellowish color of the samples taken from the Baltic Sea. Nowadays, this fraction is known as colored or chromophoric dissolved organic matter, short CDOM [14,15]. The measurement principle for CDOM absorption (an inherent optical property, or IOP, of natural water bodies) is based on the reduction of light intensity from a light source to a detector over a certain distance. It typically requires a filtered water sample, since only the dissolved and not the particulate fraction is of interest, and the latter could introduce errors due to light scattering. While in situ filtration is technically possible and practiced e.g., in underway systems [16], it is rather sophisticated and therefore not realized in today's commercially submersible CDOM sensors [17]. For a feasible, but still technically complex, approach to derive CDOM absorption in subsea or underway applications, the scattering loss of photons is suppressed by reflective tubes [18] or a reflecting cavity [19-21]. Yet in the majority of today's observing platforms and ship operated sensor systems, CDOM absorption measurements are not implemented.

The most common sensors within CTD-samplers, FerryBox systems, autonomous underwater vehicles (AUVs), gliders, biogeochemical Argo floats and alike are CDOM fluorometers. Applying a UV light source and detecting an emitted fluorescence signal at a higher wavelength (lower energy), these sensors utilize a principle that Kalle once described as 'skyblue fluorescence' [12,22]. In addition to these single-channel sensors, a few sensor systems commercially exist that enable a selection of several wavelengths pairs [17]. Recently, a matrix fluorescence sensor was presented that can sense a set of 4 detection wavelengths for three different excitation wavelengths, thus spanning a matrix of 12 combinations [23]. While CDOM fluorescence is technically speaking a correct term, it can be mixed up with CDOM (by definition an absorption property) and reports or commercial product descriptions sometimes tend to incorrectly shorten measurement devices as 'CDOM sensors'. To reflect the fact that the fluorescing part of the DOM is a subfraction of the absorbing fraction of DOM, we herein use FDOM as a designator for fluorescent DOM, as common in recent literature [9,24-26]. Laboratory measurement of FDOM is typically performed with UV-VIS spectrofluorometers $[27,28]$. They enable a free selection of excitation and detection wavelengths and thus different forms of results: (a) emission spectra (with a fixed excitation wavelength); (b) excitation spectra (with a fixed emission wavelength); (c) synchronous scans (excitation and emission changing at the same rate); and (d) excitation-emission matrices (EEM). The latter provides a full scan of a range of excitation wavelengths, performing for each of these excitation wavelengths a full emission scan. The resulting matrix of fluorescence intensities, sometimes referred to as 'optical fingerprint', is reflecting all fluorescing components and its peaks are associated with different components from the DOM pool [14,29]. A classical labeling of the fluorophores in DOM identifies five main peaks A, C, B, T, and M. Those peaks are extensively used to identify the main composition and origin of FDOM. Previous reports indicate the correlation between microbial presence and freshly produced DOM (peaks M, B and T), while allochthonous DOM has been associated to the peaks A and C [29]. EEM spectra are frequently used in recent literature $[27,28]$ and several parameters are calculated from them, including the humification index [30], biological index [31], and recently produced material index [32]. A statistical analysis of EEM spectra is often performed by parallel factor analysis (PARAFAC), a method that identifies the underlying components from a set of spectra [33,34]. EEM spectroscopy (EEMS) and its spectral analysis can be considered the state-of-the-art in FDOM assessment, however, to the best of our knowledge, no submersible sensor exists that enables the high-resolution (in terms of wavelengths intervals) measurement of excitation-emission matrix spectra with in situ equipment. 
Herein, we will present (i) design and application of a novel in situ EEMS sensor system (in memory of Kurt Kalle named the 'Kallemeter') that enables full optical fingerprints in a submersible design, and compare these results with (ii) flow-through data from two commercial FDOM sensors, and (iii) spectral components identified in surface water samples from a laboratory UV-VIS spectrofluorometer, based on a field campaign in the Trondheimsfjord, Norway.

\section{Materials and Methods}

The following section starts with a detailed description of the design of the novel 'Kallemeter' in situ EEMS sensor system, including initial laboratory measurements to illustrate its performance. To enable a comparison of bulk fluorescence detected, two commercial FDOM sensors will briefly be introduced, both operated in a commercially available flow-through sensor system (FerryBox, -4H-JENA engineering, Jena, Germany). This will be followed by a description of the laboratory methods applied on discrete water samples, and the subsequently used statistical method to derive the components of the EEM spectra observed. Finally, we will provide information about the study site itself.

\subsection{Design of an In Situ Capable EEMS Sensor System}

The newly-developed submersible EEMS sensor system provides comprehensive excitation-emission matrices for in situ fluorescence measurements of organic matter in natural waters. This subchapter presents its design, beginning with a representation of the operation mode in Section 2.1.1. Followed by this, a description of the technical implementation and the system design is given in Section 2.1.2. Section 2.1.3 presents the evaluation of the system performance.

\subsubsection{Submersible EEMS Sensor System and Modes of Operation}

Investigations on fluorescent organic matter can benefit from spatiotemporal information that enable a comprehensive interpretation of the dataset in context of environmental conditions. The 'Kallemeter' EEMS sensor system supports in situ explorations with three common modes of operation for field studies: vertical profiling, underway sensing (e.g., installed in a moonpool of a vessel), and moored operation (e.g., integrated to a subsea platform). Figure 1 shows the deployment of the EEMS sensor system in profiling mode (Figure 1a) and the deployment in a moonpool of a research vessel for in situ underway investigations (Figure $1 b, c)$. The submersible design offers automated data acquisition from water samples to a maximum water depth of $200 \mathrm{~m}$ in a freely selectable time interval, without the support of an operator. Once installed, autonomous long-term investigations from days to weeks are possible, depending on biofouling [35] of the optical sensor unit and sediment load of the water filtration unit.

\subsubsection{EEMS Sensor System Design and Technical Implementation}

The entire EEMS sensor system is designed for a stand-alone operation as an underwater unit that only needs to be supplied with electrical power from an external power source. In this way, a moored operation with an external $12 \mathrm{~V}$ DC battery pack can also be realized. In case of shipborne installations like profiling or underway measurements, the system can be connected to an on-board unit via a $200 \mathrm{~m}$ seaworthy cable, as illustrated in Figure 2a. The on-board unit provides $130 \mathrm{~V}$ DC power supply and data transmission to the 'Kallemeter' via Ethernet. This gives the opportunity to connect an external PC for remote control of the underwater unit, automatic data backup, or real-time visualization of the in situ measurements. In addition to the in situ fluorescence spectrometer unit, the 'Kallemeter' was equipped with a turbidity meter (STM/bh, Seapoint Sensors Inc., Exeter, NH, USA) and a CTD (Conductivity, Temperature, Depth) (miniCTD probe, ASD Sensortechnik $\mathrm{GmbH}$, Trappenkamp, Germany). The 'Kallemeter' housing is made of a solid PEEK (polyether ether ketone) tube with steel plates at its ends, which also support the dissipation of thermal energy to the aquatic environment through internally forced convection, as this is important to provide long-term 
stability of the measurement system (light source and optical measurement devices). The EEMS sensor system is controlled through an integrated Microsoft Windows 7 PC, digital I/O converters, and LabVIEW software (version 2013, National Instruments, Austin, TX, USA), using a custom-made control program (named 'EEMsea'). The latter allows for comprehensive adjustments of the measurement procedures, like EEM wavelengths or control of the sampling interval. All EEM datasets are stored in a comma-separated value (CSV) file format and include system- and sampling-relevant metadata in the header (e.g., sampling-identifier, internal temperature, and coefficients), which are assigned to the standardized file structure from PerkinElmer Luminescence Spectrometers ([Info], [Setup], [SampleInfo], [SampleData]; PerkinElmer, Waltham, MA, USA). Therefore, postprocessing and statistical analysis of EEM spectra can easily be applied by standard third party software or Matlab Toolboxes (The MathWorks, Natick, MA, USA) e.g., for PARAFAC [27].
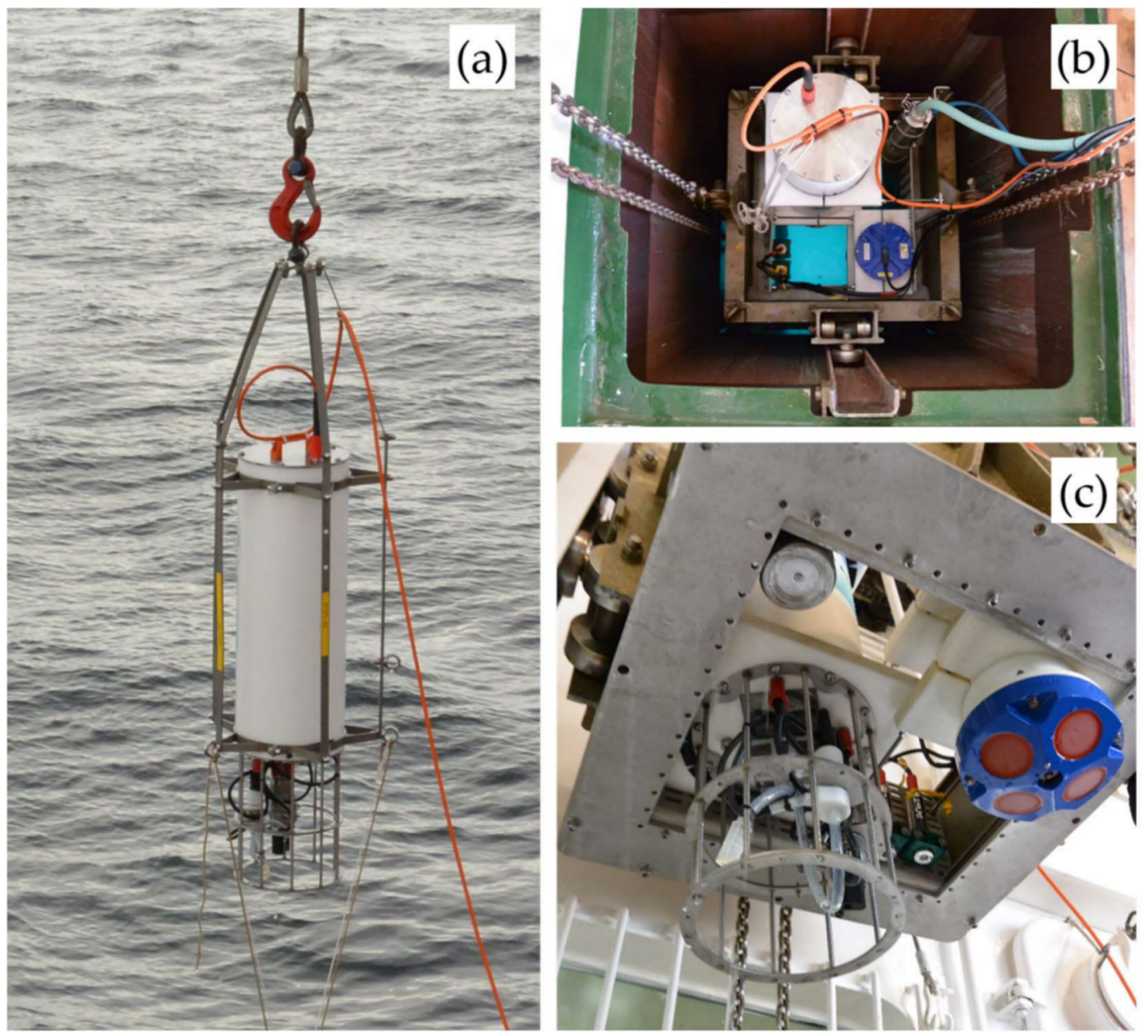

Figure 1. (a) Excitation-emission matrix spectroscopy (EEMS) sensor system in profiling mode on a winch of a research vessel. (b) EEMS sensor system, installation for in situ underway observations in the moonpool of the research vessel, top-view. Close to the EEMS sensor system, an acoustic Doppler current profiler $(\mathrm{ADCP})$ as well as the water intake pump for the FerryBox system were installed in the moonpool-frame. (c) View from below. 


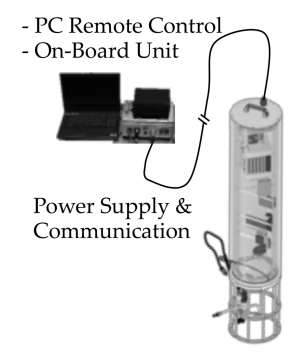

(a)

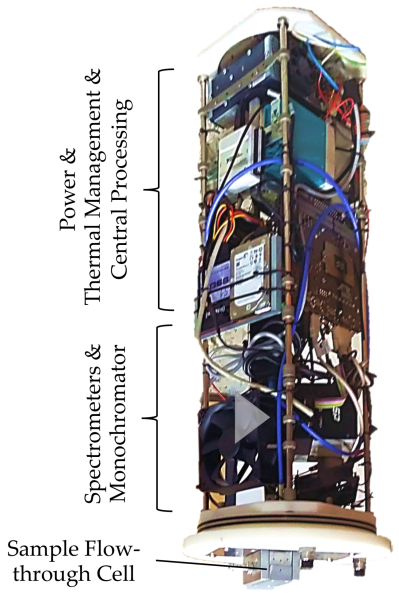

(c)

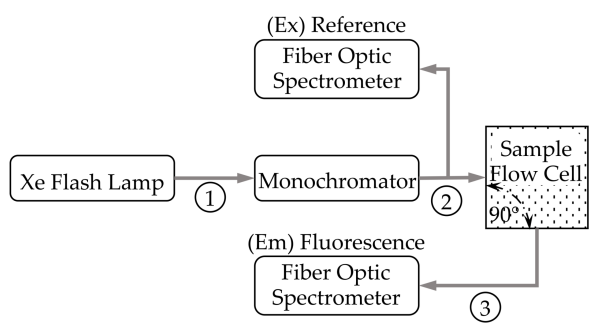

(b)

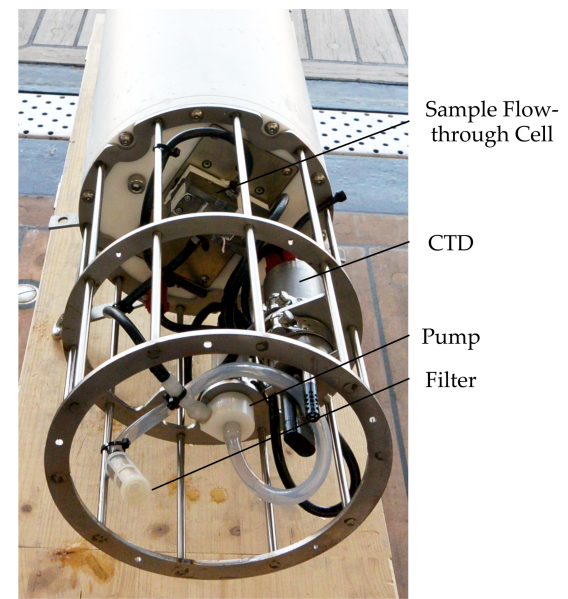

(d)

Figure 2. System components of the submersible EEMS sensor system. (a) System connected to an on-board unit and remote PC-control (optional). (b) Schematic structure of excitation-emission matrices (EEM) fluorescence spectrometer hardware and optical components (connected by optical fibers 1, 2, 3). (c) Internal close-up with electronics and optical components. (d) Close-up of the outer components of the EEMS sensor system.

The entire EEM fluorescence spectrometer design, which is presented in Figure 2b, consists of the following fluorescence measurement components: In the fluorescence excitation strand, a Xenon flash lamp (PX-2, Ocean Optics, Largo, FL, USA) is used as a broadband light source, which is coupled to a monochromator (CM 110, Spectral Products, Putnam, CT, USA) via an optical fiber (1). The output of the monochromator is coupled via an optical Y-fiber (2) to the reference spectrometer (USB2000+, Ocean Optics, Largo, FL, USA). Through this, a reference measurement of the excitation spectrum is realized. In parallel, the optical Y-fiber (2) connects the monochromator output to a flow-through sample cell in which the sample medium is located. The fluorescence emission strand consists of the detection spectrometer (QE-Pro, Ocean Optics, Largo, FL, USA) coupled via an optical fiber (3) to the sample flow-through cell. In the following, details of the fluorescence measuring system and its components are presented.

\section{Fluorescence Excitation Light Source}

Some in situ sensor designs use Xenon flash (or pulsed) lamps due to their high energy output in the ultraviolet (UV) and visible regions of the light spectrum as well as their long lifespan [36]. For these reasons, the 'Kallemeter' also utilizes a Xenon flash lamp (PX-2, Ocean Optics, Largo, FL, USA), which emits pulsed light with a continuous spectrum in a fluorescence relevant excitation wavelength range from $220 \mathrm{~nm}$ to $750 \mathrm{~nm}$. A pulse power of maximum 45 microjoules/pulse (with $5 \mu \mathrm{s}$ pulse duration at $1 / 3$ height of pulse) and a lifetime of $10^{9}$ pulses are expected for this 'expendable part' (estimated 230 days continuous operation @ $50 \mathrm{~Hz}$ pulse rate). A stable output from pulse to pulse is guaranteed for up to $100 \mathrm{~Hz}$ repetition rate, so the flash delay results in 10 milliseconds. Since the total intensity typically decreases slowly over the operating period [37], a measurement of the 
excitation spectrum is implemented to provide metadata of the EEMS sensor system status (presented in the subsection "Quality status of the excitation wavelengths").

Control of the Fluorescence Excitation Band

A monochromator (Type CM 110, Spectral Products, Putnam, CT, USA) is used to separate a narrow excitation band from the spectrum of the Xenon flash lamp. A full width at half maximum (FWHM) effective bandwidth of $10 \mathrm{~nm}$ is realized (therefore no slits are used) and the excitation wavelengths are selectable from $200 \mathrm{~nm}$ to $750 \mathrm{~nm}$ in $1 \mathrm{~nm}$ steps (with ruled grating AG1200-00300-303). The monochromator provides a coupling and decoupling angle of $14.8^{\circ}$ and results to 0.13 numerical aperture (NA).

\section{Quality Status of the Excitation Wavelengths}

A wavelength-calibrated reference spectrometer (USB2000+, Ocean Optics, Largo, FL, USA) controls the quality status of the excitation. The internally used grid provides a spectral sensitivity range from $200 \mathrm{~nm}$ to $800 \mathrm{~nm}$ with a fixed slit width of $100 \mu \mathrm{m}$, and a possible integration time from 1 millisecond to $65 \mathrm{~s}$. Reference data are recorded in parallel to the fluorescence measurements but are not included in the calculation of the EEM spectra. Instead, they only serve as metadata for monitoring the quality of the excitation light source state over the operation time.

Water Sampling Flow-Through Cell

Various conceptual instrument designs and principles for fluorescence detection hardware are available for different applications: right angle detection, intersecting cones, flow-through, and fiber optic designs [36]. The 'Kallemeter' sample flow-through cell design combines right angle detection (the commonly used $90^{\circ}$ emission-excitation setup in luminescence spectrometry) with fiber optics and intersecting cones in a closed flow-through design, which is illustrated in Figure 3a. In addition, the measuring cell makes use of well-directed multireflective intersections of the optical fiber aperture to achieve multiple excitations and detection cone overlaps. Thus, the optical path within the water sample is enhanced and an effective increase of factor 2.5 of the fluorescence signal for the highest signal-to-noise ratio can be achieved (Appendix A, Table A1). Two mirror elements are used for this purpose, which are arranged opposite to the optical fiber terminations in a way that no direct fluorescence excitation light can enter in the optical fiber of the detector strand. A concave mirror (CM127-025-F01 - Ø1/2" UV Enhanced Al-Coated, $\mathrm{f}=25.0$, Thorlabs, Newton, NJ, USA) is used in (opposite) combination to the excitation cone. With a focal length of $25 \mathrm{~mm}$, the focus point of the selected concave mirrors is almost at the end of the optical fibers distance of $22 \mathrm{~mm}$. A planar mirror (PF05-03-F01 - Ø1/2" UV Enhanced Al-Coated, Thorlabs, Newton, NJ, USA) is used in (opposite) combination to the emission cone of the optical fibers.

As the sample cell forms the contact point between the optical parts and the water sample, it is installed in a separate housing at the bottom of the EEMS sensor system (see Figure 2c,d). Thus, a decoupling of the fluid-carrying and pressurized parts from the sensitive internal structures of the measurement unit is achieved and a simple sealing and pressure tightness can be realized. The optical interfaces of the sample cell, which are in contact with a seawater sample, are covered with superior transparent quartz glass windows (\#45-310. TECHSPEC, Ø $15 \mathrm{~mm}$ Uncoated, $1 \lambda$ Fused Silica Window, Edmund Optics, Barrington, NJ, USA). In order to ensure biogeochemical inertness of the sample cell, a specific adhesive (LS2-6140, NuSil Technology, Carpinteria, CA, USA) was selected through in situ tests as a suitable material for connecting the sample cell components and quartz windows. Even after several days in aqueous solution, this adhesive did not emit any fluorescent substances. 


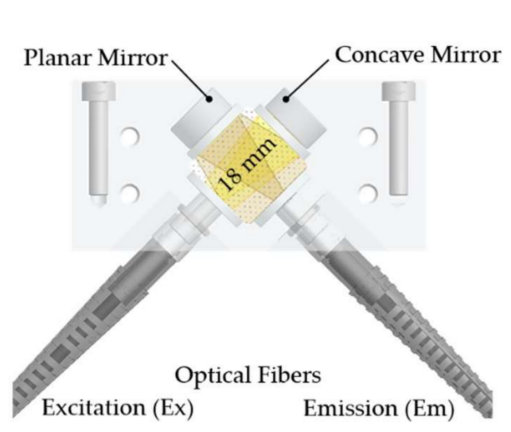

(a)

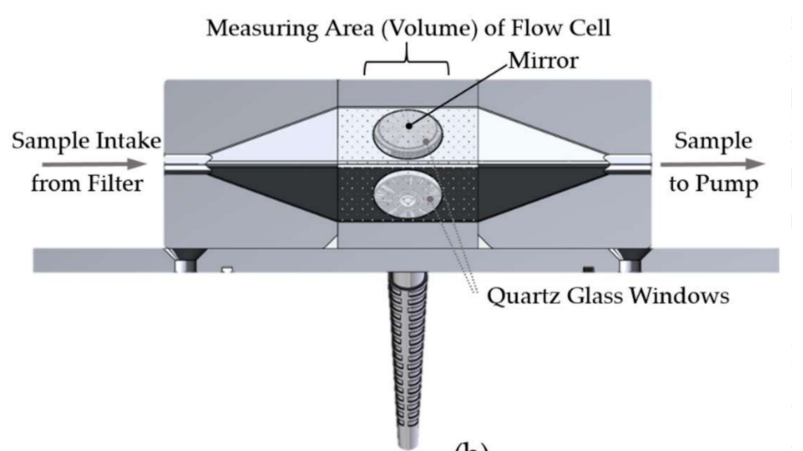

(b)

Figure 3. Details of the EEMS sensor system sample flow-through cell. (a) Measuring area-section with right angle arrangement of the excitation and emission optical fibers including the concave and planar mirror, respectively. (b) Cut-section through the flow-through cell with media intake and quartz glass windows.

The flow-through geometry type results in a greater efficiency in signal output compared to an open-faced design. Thus it is a good choice for waters with a wide range of NOM concentrations and low numbers of particles, as the sensor geometry (sample volume) is well defined [36]. A closed flow-through cell design, as illustrated by the cut-section in Figure 3b, provides shading of the optical inner parts from ambient light. This is a further benefit for an in situ application as it reduces the effect of biofouling [38]. During the sampling process, the closed sample cell is flushed with the water sample. The inlet side of a mini submersible pump for profiling applications (SBE 5M-1, Sea-Bird Scientific, Bellevue, WA, USA) is connected to the water outlet of the sample cell, while a reusable $50-\mu$ m nylon screen filtration element (type series F20 filter housing, Wolftechnik Filtersysteme, Germany) is connected to the sample cell water inlet via opaque hoses. This prevents an uncontrolled exchange between the ambient water and the water sample volume during an EEM spectrum measurement. This is particularly important for in situ underway operations when the 'Kallemeter' moves through different water bodies during an ongoing EEM measurement. Note that the setup presented herein was not equipped with a $0.2 \mu \mathrm{m}$ or $0.45 \mu \mathrm{m}$ filter, as recommended to separate the dissolved from the particulate fraction of organic matter. This is also the case for common bulk fluorescence sensors, as used in this study for comparison. However, as a pumped flow-through system, the 'Kallemeter' is generally capable of such a filtration unit as used e.g., for in situ spectral absorption measurements of CDOM [17].

\section{Main Fluorescence Detector}

The main fluorescence detector unit of the 'Kallemeter' EEMS sensor system is a wavelengthcalibrated CCD digital spectrometer with a high dynamic range of 85.000:1 (QE-Pro, Ocean Optics, Largo, FL, USA). The fluorescence emitted by the water sample is transmitted via an optical fiber, which is installed at the sample flow-through cell. The spectrometer built-in grating enables the detection in a full range of emission wavelengths from $200 \mathrm{~nm}$ to $950 \mathrm{~nm}$, which corresponds to the detection range of commonly used laboratory luminescence spectrometers (e.g., the LS55, PerkinElmer, Waltham, MA, USA). The slit of the detector spectrometer has a width of $100 \mu \mathrm{m}$. Long-term stability and noise reduction is achieved by internal Peltier cooling of the detector to $-10^{\circ} \mathrm{C}$, as all fluorescence measurements signals are subject to alterations as a function of temperature. Temperature changes can arise either from self-heating of the instrument or from changes in ambient temperature of the deployment environment. Integration times of 8 milliseconds up to $60 \mathrm{~min}$ are selectable to enable stable measurements for environments where sample signal intensity is small. The spectrometer includes further a second order wavelength filter, preventing detection of Rayleigh and Raman scattering of higher orders.

The chosen detector spectrometer offers automatic dark measurements without external shutter units, which is used to obtain related metadata to correct for instrument response variables. As a routine by the 'EEMsea' software, a dark count measurement is carried out once initially per EEM 
spectrum measuring cycle and is automatically subtracted from the fluorescence data. Investigations of wavelength assigned intensity dark count measurements are presented in Appendix A, Figure A1 through a long-term measurement test $(116 \mathrm{~h})$ exhibiting stable operating conditions with no drift or significant invariance over time.

\section{Optical Fibers}

Optical fibers in the system setup are solarization-resistant, as ultraviolet radiation below $260 \mathrm{~nm}$ degrades transmission in silica fibers, also known as UV degradation. The custom-made designs, as illustrated in Figure 4a, provide maximum fiber diameters (80 single fibers $200 \mu \mathrm{m}$ core diameter, Ø $2.6 \mathrm{~mm}$ bunch, LOPTEK, Berlin, Germany) and achieve a high transmission (96\%) in all relevant excitation wavelengths (labeled (1) in Figure 2b). The numerical aperture is NA $=0.22$. Figure $4 \mathrm{~b}$ shows the optical Y-fiber and the single $80 \mu \mathrm{m}$ fiber to the reference spectrometer that measures the reference excitation spectrum (labeled (2) in Figure 2b). This constellation prevents super-saturation or even damage of the reference spectrometer. For the fluorescence emission (detection) strand, a conventional optical fiber is used (QP1000-2-UV-Vis, Ocean Optics, Largo, FL, USA), connecting the sample flow-through cell to the main fiber optic spectrometer (labeled (3) in Figure 2b).

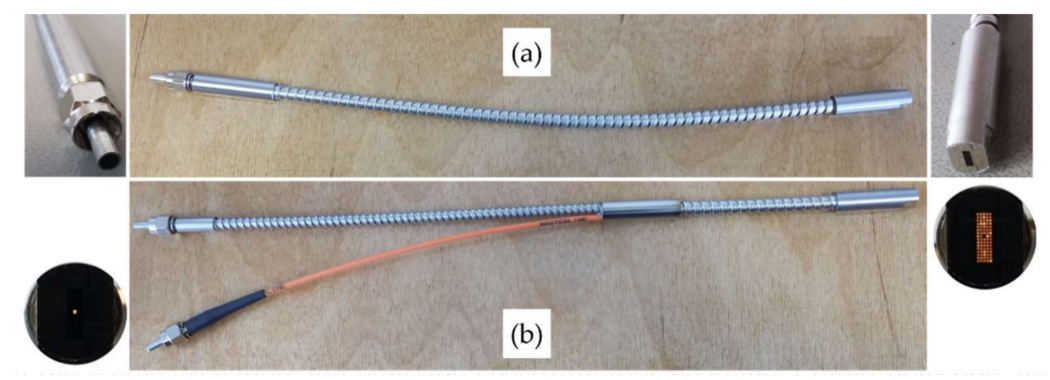

Figure 4. (a) Optical fiber coupling of the Xenon flash lamp with the monochromator (labeled (1) in Figure 2b). (b) Optical Y-fiber coupling of the monochromator with the reference spectrometer and the water sample flow-through cell (labeled (2) in Figure 2b).

\subsubsection{EEMS Sensor System Fluorescence Performance Evaluation}

As the complete 'Kallemeter' EEMS sensor system is based on a new design, the system performance for wavelength calibration, fluorescence intensity and signal-to-noise ratio was examined prior to field application. Considering the main focus of this article being the field application, the most important facts and a compilation of regularly practiced calibration methods for the in situ EEMS sensor system will be presented in the following section. All settings for the following measurements are listed in detail in Table A2 of the Appendix A.

The general procedure to calibrate an in situ fluorometer consists of (i) precalibration with tests of pressure, mechanical, and electronic stability as well as precision, (ii) signal output calibration to measure the dark and maximum counts, (iii) internal temperature calibration, (iv) determination and record of offset values with purified water at different temperatures, and (v) manufacturer calibration to obtain the scale factor of the fluorometer [36]. Calibration should be repeated in regular intervals, because environmental conditions can vary and lamp as well as spectrometer performance can degrade over time. Table 1 summarizes the EEMS sensor system specifications.

\section{Signal-To-Noise Ratio}

The signal-to-noise ratio ( $\mathrm{S} / \mathrm{N})$ of the Raman band of tap water is easy to realize and a widely used method to quantify the sensitivity of a spectrofluorometer [39,40]. The $\mathrm{S} / \mathrm{N}$ (where $\mathrm{S}$ denotes signal intensity and $\mathrm{N}$ noise intensity) of the Raman band is calculated with the following equation.

$$
\mathrm{S} / \mathrm{N}=(\mathrm{S}-\mathrm{N}) / \sqrt{ } \mathrm{N}
$$


For the 'Kallemeter' a S/N of 34 was determined for the Raman band measurement of tap water as presented in Figure A2.

Table 1. Overview of the 'Kallemeter' EEMS sensor system, fluorescence hardware specifications.

\begin{tabular}{ll}
\hline Parameter & Specification \\
\hline Light source & Pulsed Xenon flash, 9.9 Watts \\
Excitation range & $220-750 \mathrm{~nm}$ \\
Excitation bandpass & $10 \mathrm{~nm}(\mathrm{FWHM})$ \\
Excitation monochromator & Czerny-Turner design, $110 \mathrm{~mm}$ focal length \\
Excitation wavelength precision / accuracy & $0.2 \mathrm{~nm} / \pm 0.6 \mathrm{~nm}$ \\
Emission range & $200-950 \mathrm{~nm}$ \\
Emission bandpass & None (full set of wavelengths) \\
Emission detection spectrograph & (QE-Pro), Fixed, 101 mm focal length \\
Emission detector & TE-cooled CCD fiber optic spectrometer \\
Emission integration time & 8 ms to 60 min \\
Excitation reference measurement & (USB2000+), CCD fiber optic spectrometer \\
Sensitivity & Water-Raman S/N 34 \\
\hline
\end{tabular}

Wavelength Calibration

The wavelength calibration of the EEMS sensor system needs no special adjustments by the user, as both spectrometers used are calibrated by the manufacturers and therefore are supplied with a set of calibration coefficients. For verification we performed a laboratory check with a reference standard for molecular fluorescence spectrophotometry (Compound 610; excitation: $440 \mathrm{~nm}$; emission: $480 \mathrm{~nm}$; nominal concentration of $1 \times 10^{-6} \mathrm{M}$, Starna Scientific Ltd., Ilford, UK), data not shown. Such a measurement allows the evaluation of the EEMS optical setup over time and corresponding correction methods for the emission wavelengths.

Intensity Calibration with Suwannee River Standard

Since 1982, representatives of the International Humic Substance Society (IHSS) have isolated reference fulvic acids, humic acids, and natural organic matter (NOM) from the Suwannee River in southeastern Georgia, USA. Suwannee River has a remarkable low variance in its elemental composition and is therefore a commonly accepted standard. It has a long history as reference material for multidisciplinary research areas, including the marine community [41]. For the fluorescence measurement of the 'Kallemeter', a sulfuric acid dilution of Suwannee River (sample charge number $2 \mathrm{~S} 101 \mathrm{H}$ ) was used with concentrations of $2.5 \mathrm{ppm}$ and $25 \mathrm{ppm}$. The EEM spectra of the two concentrations of Suwannee River standard are shown in Figure 5. Receiving reasonable signal intensity in both samples indicated sufficient signal intensity for nominal concentrations at marine study sites.
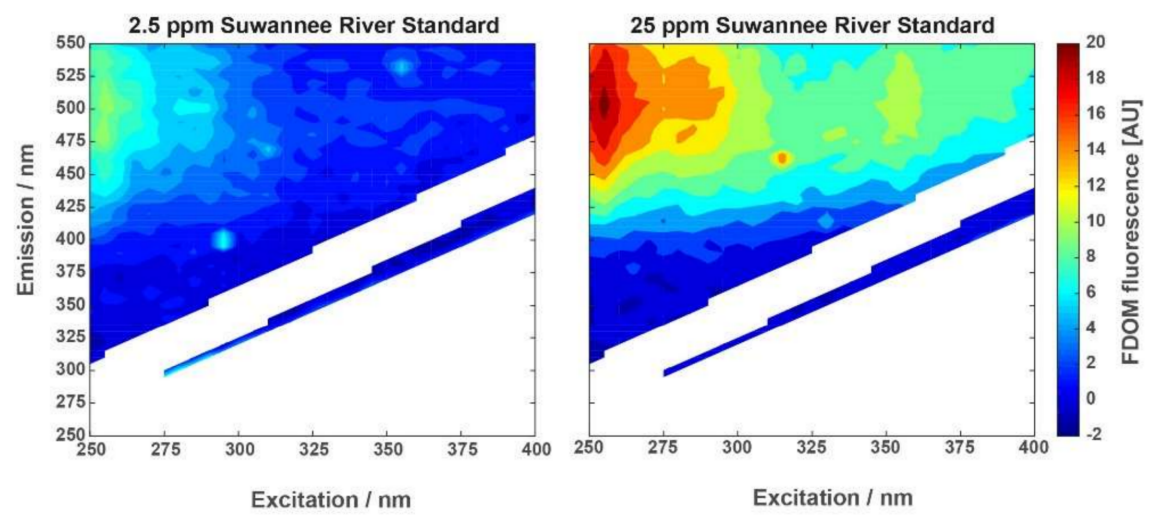

Figure 5. EEM spectra for two concentrations of Suwannee River standard. Excitation wavelengths were used for the $\mathrm{x}$-axis, while emission wavelengths were applied for the $\mathrm{y}$-axis [42]. Color bar (z-axis) denotes relative fluorescence intensity. 


\subsection{FerryBox-Based Organic Matter Fluorescence Measurements}

An important step in the evaluation of the 'Kallemeter' is the comparison with other existing sensors and approaches, here with two commercially available sensors, the Cyclops-7-U (Turner Designs, San Jose, CA, USA) and the MatrixFlu-UV (TriOS, Rastede, Germany) mounted in a FerryBox system (4H-JENA engineering, Jena, Germany) installed on the ship during the research cruise (see Section 2.3). Furthermore a LS-55 spectrofluorometer (PerkinElmer, Waltham, MA, USA) was used as a common standard for laboratory measurements (see Section 2.4), providing complete EEM spectra directly comparable with the 'Kallemeter'. The FDOM sensors either provide only certain parts of the full EEM (MatrixFlu-UV) or only bulk fluorescence data (Cyclops-7-U).

As described previously [43], there are two versions of the MatrixFlu sensor, one for the visible wavelengths, with a focus on phytoplankton, and one for the ultraviolet, dedicated to FDOM components. The latter is used here and referred to as MatrixFlu-UV. The fundamental idea is to measure the typical peaks of organic matter fluorescence, as described by Coble [29], instead of assessing the whole excitation and emission spectrum, thus enabling a rapid detection and a high temporal resolution. This section describes only the sensor's main features, as its technical design has been published elsewhere $[23,44]$.

The MatrixFlu-UV sensor consists of an excitation light source with distinct wavelengths combined with a set of detectors collecting a near field emission of a fluorescence signal at certain wavelengths directly in the water column (open sensor interface). Each combination of an excitation and emission wavelength results in a different fluorescence channel. The optical part contains a single semiconductor device emitting light at three different wavelengths $(254 \mathrm{~nm}, 280 \mathrm{~nm}$, and $320 \mathrm{~nm}$ ) on the same optical axes. Four single semiconductor detectors are arranged around it collecting the fluorescent signal in an angle of approx. $170^{\circ}$ to the optical axes. Different wavebands are selected via customizable narrow bandwidth filters (here $280 \mathrm{~nm}, 360 \mathrm{~nm}, 460 \mathrm{~nm}$, and $540 \mathrm{~nm}$ ). By doing this, all possible combinations result in twelve different channels.

FDOM components referred to in this work are mainly associated to (a) terrestrial or old marine humic-like substances (peak C), (b) "freshly produced" marine humic-like substances (peak M), and protein-like Tryptophan substances (peak T) [45,46]. Humic components show a further related excitation maxima for UV light of higher energy (lower wavelength) but same emission position or range (peak A) [45]. Data from all MatrixFlu-UV channels are collected simultaneously. For the comparison with the 'Kallemeter' and the other bulk fluorescence sensor (described below), Channel 11 was extracted and evaluated, corresponding to peak C (EX/EM $320 \mathrm{~nm} / 460 \mathrm{~nm}$ ). Data was averaged on every minute values and smoothed by a moving mean filter (window size 13). Factory calibration and further information about the sensor performance are available in [23].

The Cyclops-7-U sensor estimates bulk FDOM concentration by measuring the fluorescence emission at $470 \mathrm{~nm}$ (60 nm peak width) for an excitation at $325 \mathrm{~nm}$ (120 nm bandwidth filter [47]). Thus, for a comparison with the data from this sensor, the 'Kallemeter' in situ EEM signal in the area corresponding to an excitation of 265 to $385 \mathrm{~nm}$ and an emission of 440 to $500 \mathrm{~nm}$ have been integrated. This provides a 'Kallemeter' derived bulk fluorescence signal that corresponds to the excitation and emission ranges given in the specifications of the Cyclops-7-U sensor.

\subsection{FerryBox Installation and Other Oceanographic Parameters Measured}

The water intake of the FerryBox was realized in the moonpool of the research vessel (in approx. $4 \mathrm{~m}$ depth) close to the measuring head of the submersed 'Kallemeter' to ensure a comparability of the measurements between the three types of instruments. Besides the FDOM data, readings of standard oceanographic parameters, such as temperature, salinity, and chlorophyll $a$ fluorescence were also obtained. All FerryBox data were averaged on minutely values and smoothed by a moving mean filter (window size 11). 


\subsection{FDOM Laboratory Water Samples}

Sampling from the near surface water, here defined as the samples collected between 0.1 and $2.0 \mathrm{~m}$, was obtained with a submersible pump system and stored in $5 \mathrm{~L}$ white plastic bottles, at all stations. Samples were filtered in the laboratory immediately after sampling, and stored at $4{ }^{\circ} \mathrm{C}$ in previously rinsed glass bottles. CDOM absorption and EEM spectra measurements were completed within $24 \mathrm{~h}$ after sampling.

Samples were filtered with a glass syringe device through GF/F Nucleopore filters $(0.2 \mu \mathrm{m}$, GE Healthcare Whatman, Piscataway Township, NJ, USA). CDOM absorbance spectra were obtained between 220 and $650 \mathrm{~nm}$ at $5 \mathrm{~nm}$ intervals on a Shimadzu UV-2550PC UV-VIS spectrophotometer (Shimadzu, Kyoto, Japan) with $10 \mathrm{~cm}$ quartz cuvettes. All measurements were performed at room temperature using freshly produced ultrapurified water (UPW; Milli-Q 185plus water purification system, Merck Millipore, Burlington, MA, USA) as reference. CDOM absorption was calculated by multiplying absorbance by $2.303 / r$, where $r$ is the cuvette length (in meter). FDOM EEM spectra measurements were conducted at room temperature on a LS55 spectrofluorometer (PerkinElmer, Waltham, MA, USA) equipped with a Xenon flash lamp, pulsed at line frequency of $60 \mathrm{~Hz}$. The excitation (EX) and emission (EM) scanning ranges were set to 200 to $400 \mathrm{~nm}(5 \mathrm{~nm}$ interval) and 220 to $550 \mathrm{~nm}$ (0.5 nm interval), respectively. The scanning speed was $1200 \mathrm{~nm} \mathrm{~min}^{-1}$, the EX and EM slit was set to $10 \mathrm{~nm}$, and the detector gain was at medium range $(775 \mathrm{~V})$. Daily measurements of UPW were used as references. Water Raman scatter peaks were eliminated by subtracting the EEM spectra of UPW blanks. Inner filter effect and Rayleigh scatter peaks were corrected using the drEEM toolbox [33]. Lamp variations were normalized to the Raman peak integral (EX: $350 \mathrm{~nm}$ ) using freshly produced UPW, therefore producing normalized intensities in Raman units (RU) [39]. EEM spectra were resized due to high S/N in certain regions. Therefore, excitation wavelengths below $250 \mathrm{~nm}$ and emission wavelengths below 300 and above $550 \mathrm{~nm}$ were excluded from the subsequent PARAFAC modeling process.

PARAFAC modeling was performed with the drEEM toolbox (ver.0.2.0) in MATLAB R2015b (The MathWorks, Natick, MA, USA) according to a method described previously [33], employing the $\mathrm{N}$-way toolbox as the engine of the PARAFAC algorithm [34]. A three-component model was validated by split-half analysis, random initialization analysis, and residuals analysis. The model explained up to $99.95 \%$ of the variability within the lab-based LS55 spectrofluorometer EEM dataset.

A similar PARAFAC analysis was applied on the Kallemeter-based EEM spectra along cruise track between station 11 and 15 . Correction for inner filter effects was realized by utilizing the measured absorption spectra from the nearest station and using Kallemeter blank measurements from an initial laboratory test with purified water. Four out of 48 spectra were excluded from the analysis, due to high residual error and leverage load, validating a two-component model that explained up to $61 \%$ of the variability within the dataset through split-half analysis, random initialization analysis, and residuals analysis. A third component could not be detected.

\subsection{Study Site}

In order to assess the performance of the 'Kallemeter' in comparison with the MatrixFlu-UV and the FerryBox-mounted Cyclops-7-U fluorescence sensors in the field, the data obtained during an expedition (HE491) with research vessel R/V Heincke from the coastal sea into the Trondheimsfjord (Norway) were analyzed. Figure 6 shows a map of the study site and the cruise track investigated. The instruments were in parallel operation from 19th to 25th of July 2017. The Trondheimsfjord is the third-largest fjord in Norway with a length of $140 \mathrm{~km}$, a volume of $235 \mathrm{~km}^{3}$, and a surface area of $1420 \mathrm{~km}^{2}$. It is divided in three basins and has a seaward sill depth of $195 \mathrm{~m}$ [48]. It is characterized by comparably high CDOM concentrations as well as vertical and horizontal gradients [49], making it an ideal test site. 


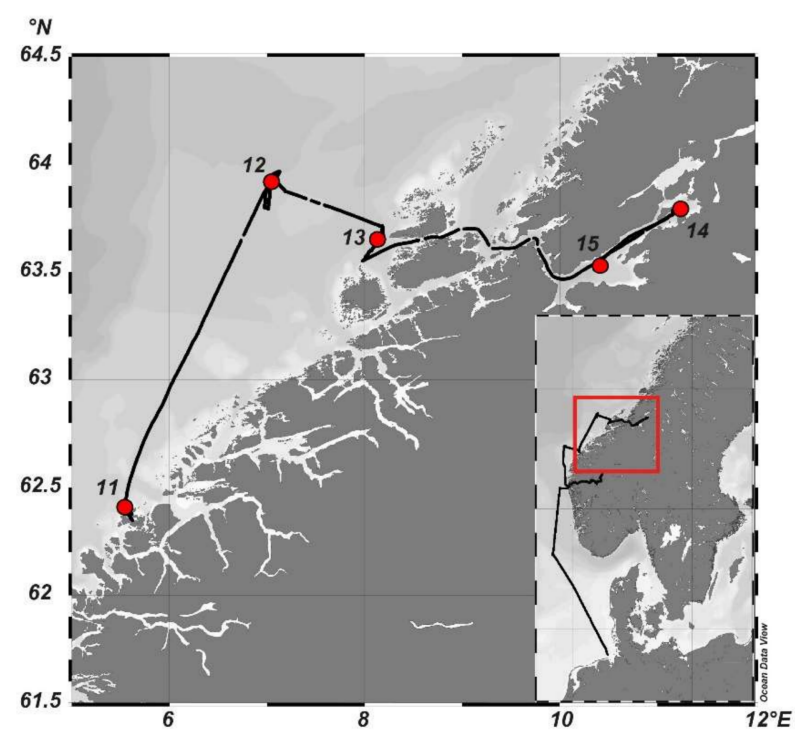

Figure 6. Overview of the study area (insert). Map shows Trondheimsfjord and its adjacent coastal sea with cruise track (solid black line) and stations (red dots) of R/V Heincke expedition HE491.

\section{Results}

The FerryBox data is well suited to provide a first overview of the overall fjord hydrography. The FerryBox dataset started on 19 July in the Norwegian coastal sea (station 11) heading first northwards (station 12) and then into the Trondheimsfjord (station 13), through the mid-fjord section and towards the innermost part of the fjord (station 14). From there, the transect went back to the mid-section and ended at station 15 on 25 July. There is a considerable difference in all parameters measured between the area outside and within the fjord (Figure 7), indicating the presence of two water bodies with different properties. With the exception of salinity, values of all parameters are higher within the fjord. Salinity is highest towards the ocean side, with values of more than 32, rapidly decreasing inside the fjord towards the mid-section exhibiting values of around 24 . Temperature increases slightly from around $14^{\circ} \mathrm{C}$ in the outer section towards 15 to $17^{\circ} \mathrm{C}$ in the mid- and inner-part of the Trondheimsfjord. Chlorophyll-a fluorescence (here provided in AU, as the sensor has not been specifically calibrated for chl-a before the cruise) shows a gradual increase from the seaward part of the fjord to a maximum at the end of the fjord. FDOM from the Cyclops-7-U fluorometer (provided in AU) shows, inverse to salinity, a four-fold increase and steep gradient from the seaward side of the fjord towards the mid- and inner-part.

Comparing the 'Kallemeter' bulk fluorescence signal extracted from the EEM spectra against the bulk fluorescence signal of the MatrixFlu-UV channel 11 and the FerryBox inbuilt Cyclops-7-U FDOM sensor data (Figure 8), it can be seen that all three signals showed a steep increase on 23 July, when entering Trondheimsfjord. MatrixFlu-UV exhibited a maximum at the end of that day, followed by a decrease on 24 July towards a steady level around half of the signal range. FDOM bulk fluorescence from the FerryBox inbuilt Cyclops-7-U sensor increased in the same steep way towards a higher level on 23 July. Signal intensity stayed on this level with only a slight decrease in the morning of 24 July. 'Kallemeter' bulk fluorescence signal, as indicated by red stars, exhibited the same dynamical behavior as the Cyclops-7-U. A linear regression analysis was performed (Figure 9) of the extracted 'Kallemeter' bulk fluorescence against the Cyclops-7-U sensor (coefficient of determination $R^{2}=0.96$ ) as well as the corresponding channel of the MatrixFlu-UV $\left(R^{2}=0.88\right)$, both attached to the flow through system. 

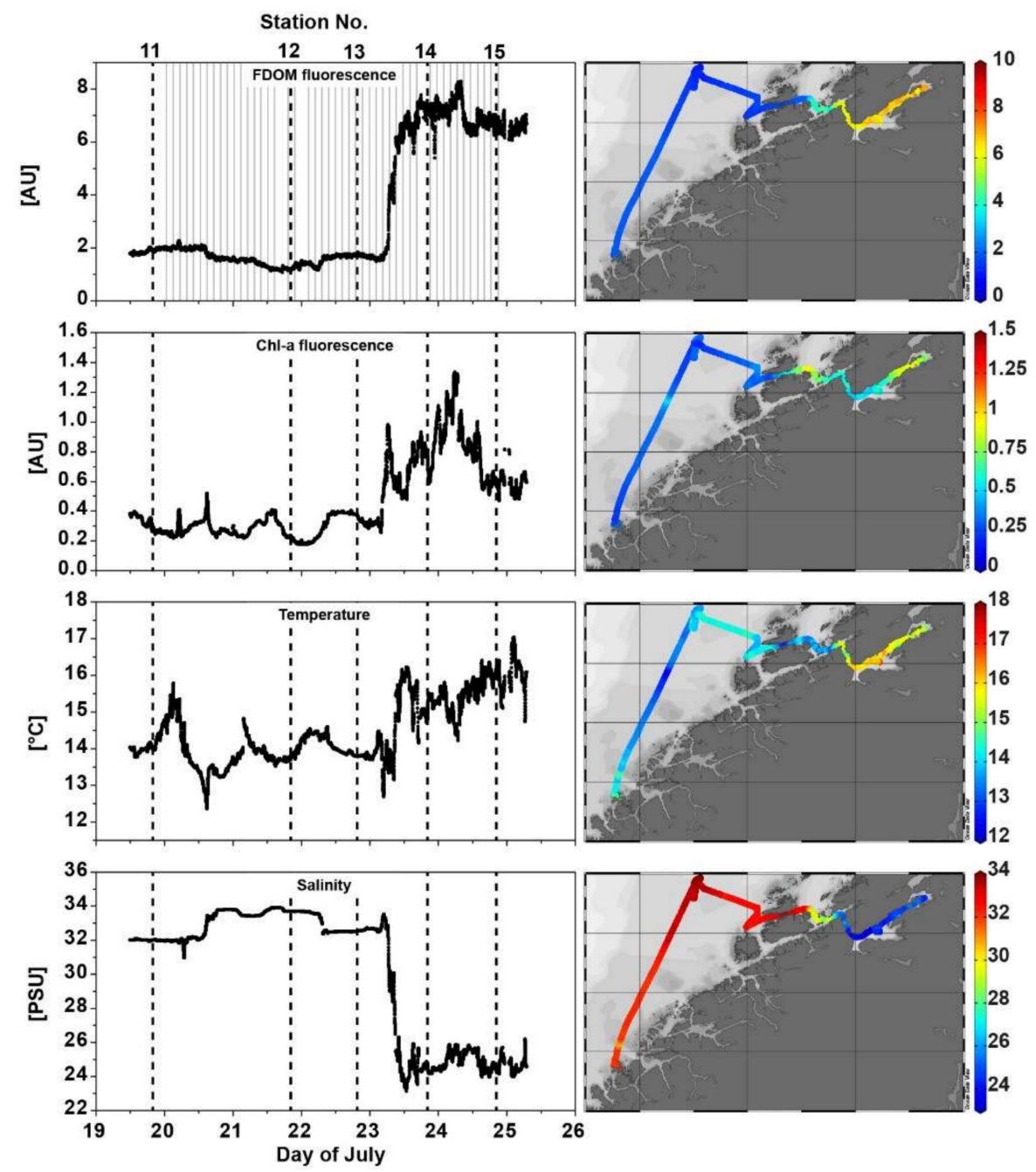

Figure 7. Underway oceanographic data measured by the FerryBox. From top to bottom: Fluorescent dissolved organic matter (FDOM) from the Cyclops-7-U bulk fluorometer, chlorophyll a fluorescence, temperature, and salinity. The left panels display the data as time series, the corresponding right ones as a map plot. Dashed lines indicate the stations where water samples were collected. Gray lines in the top-left panel indicate availability of the in situ Kallemeter-based EEM spectra $(\mathrm{N}=48)$.

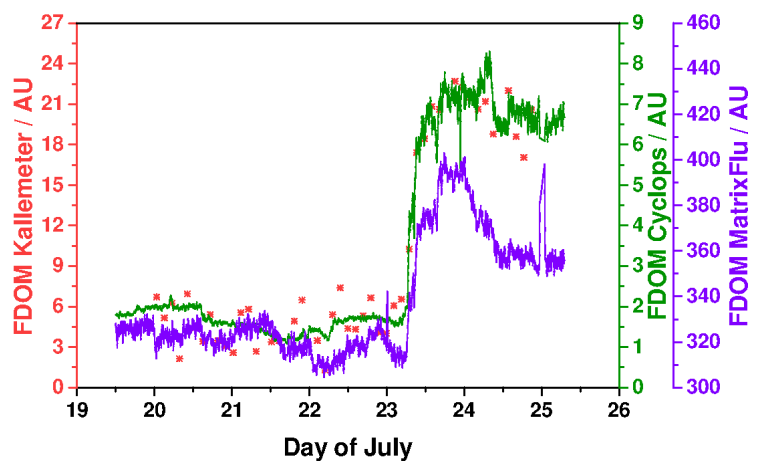

Figure 8. Comparative view on the extracted underway measurements from the MatrixFlu-UV (violet), the FerryBox FDOM Cyclops-7-U sensor (green) and the extracted bulk fluorescence signal from the EEM spectra (red stars), obtained along a transect from the Norwegian coastal sea into the Trondheimsfjord. 

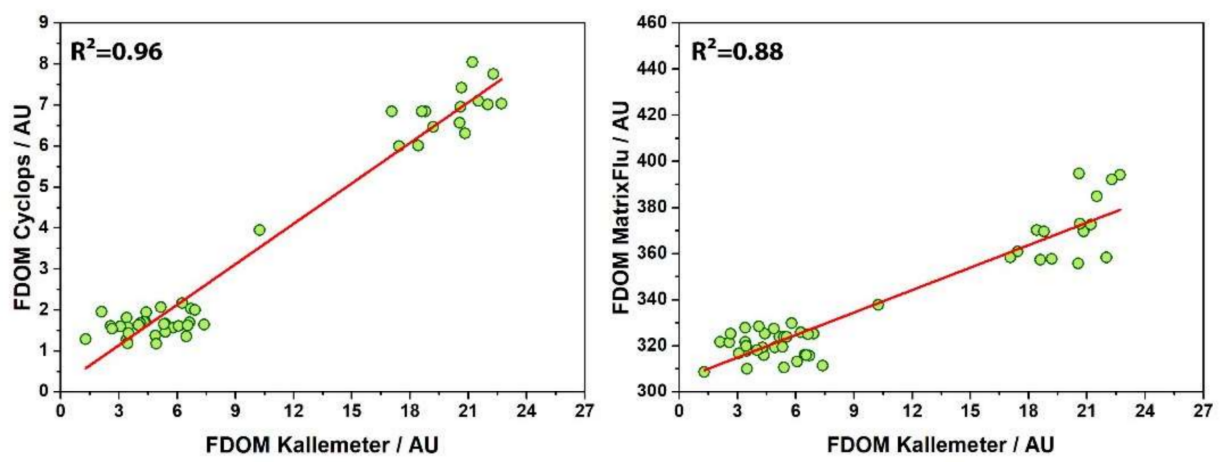

Figure 9. Comparison of extracted 'Kallemeter' bulk fluorescence signal against FerryBox FDOM Cyclops-7-U sensor (left panel) as well as the corresponding channel of the MatrixFlu-UV (right panel). Red lines represent the results of a linear regression.

In situ underway EEM measurements, measured by the 'Kallemeter' in the moonpool of R/V Heincke, provided a total of 48 spectra in 5 days ( 20 to 25 July). All fluorescence information and metadata were continuously recorded from open water into the Trondheimsfjord. A comparison of normalized EEM spectra of the lab-based LS55 fluorometer with the corresponding nearest normalized Kallemeter-based EEM spectra at stations 12-15 (Figure 10; station 11 had no close match-up within a time frame of $\pm 1 \mathrm{~h}$ ) shows good similarity for stations 14 and 15, where signal intensities are 5 -times higher as compared to stations 12 and 13 (compare Figure 8). These lower concentrations of fluorescent organic matter at stations 12 and 13 were only resolved from the apparently more sensitive laboratory LS55 spectrofluorometer, thus illustrating the current limits of the 'Kallemeter' with respect to low concentrations and the effects of noise. Please note that we applied normalization to the EEM spectra to enable a comparison of spectra signatures measured, independent from the signal strength. A non-normalized set of 'Kallemeter' EEM spectra is provided in the appendix (Figure A3) showing for every fourth dataset (a) an EEM spectra with EX wavelengths 230-550 nm, $\Delta \lambda=10 \mathrm{~nm}$, integration time of $60 \mathrm{~s}$ and two averaged scans, slit $=10 \mathrm{~nm}$, EM wavelengths 189-990 nm, and (b) an emission scan with EM wavelengths 189-990 nm for $250 \mathrm{~nm}$ EX wavelength. These Kallemeter-based EEM spectra show an increase in fluorescence intensities inside Trondheimsfjord as compared to the coastal water conditions in the EM wavelength range from 400 to $550 \mathrm{~nm}$.

PARAFAC analysis of the lab-based LS55 spectrofluorometer EEM spectra from water samples gathered at different depths demonstrated the presence of three main components $(C 1, C 2$, and $C 3)$ in the water samples (Figure 11, top panel). These components were characterized by their excitation and emission pairs (EX/EM) as follows. Component (C1) corresponding to terrestrial humic-like peaks $\mathrm{A}_{C}$ and $C$, component (C2) corresponding to marine humic-like peaks $A_{M}$ and $M$, and component $(C 3)$ corresponding to protein-like Tryptophan peak T, as suggested by Coble [29]. The spectral composition of the recorded lab-based LS55 spectrofluorometer EEM spectra (provided in Table 2) shows that the fluorescent intensity of the peaks $\mathrm{C} 1, \mathrm{C} 2$, and C3 remains constant between the open ocean stations (ST11 and ST12) and the outer section of the fjord (ST13). Once the mid- and inner-part of the fjord was reached, we recorded a sharp increment (by a factor of 5) in the fluorescent intensity for the components C1 and C2 (ST14 and ST15), while C3 stays nearly constant.

Performing PARAFAC analysis of the Kallemeter-based EEM spectra along the transect resulted in a model with two components validated (Figure 11, bottom panel). These components, even though influenced by the noisy EEM spectra that suited as model dataset, can be related according to their excitation/emission pairs to the presence of terrestrial humic-like peaks $A_{C}$ and $C$, and marine humic-like peaks $A_{M}$ and $M$. Although reasonable EEMS where produced by the 'Kallemeter', the presence of noise and suspended materials in the samples must be addressed in the future, in order to minimize the observed displacement on the peak's position. 

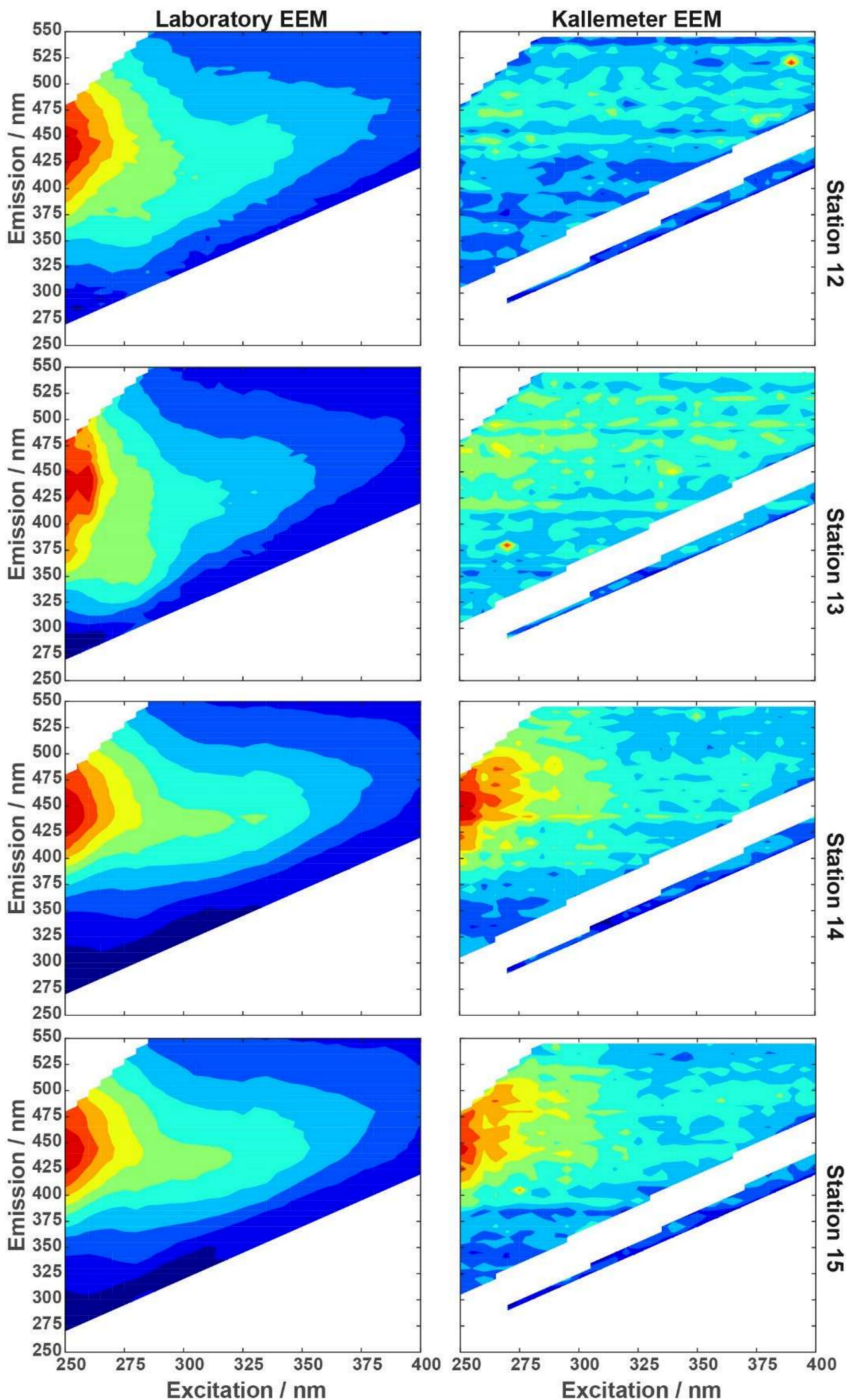

Figure 10. Normalized EEM spectra from lab-based water sample analysis with the LS55 laboratory spectrofluorometer (left) and nearby (match-up of $\pm 1 \mathrm{~h}$ ) in situ measurements with the Kallemeter (right) for stations 12-15 of R/V Heincke expedition HE491 along a transect from the coastal ocean into the Trondheimsfjord. Notice that FDOM intensity in stations 14 and 15 are 5-times higher compared to stations 12 and 13. 

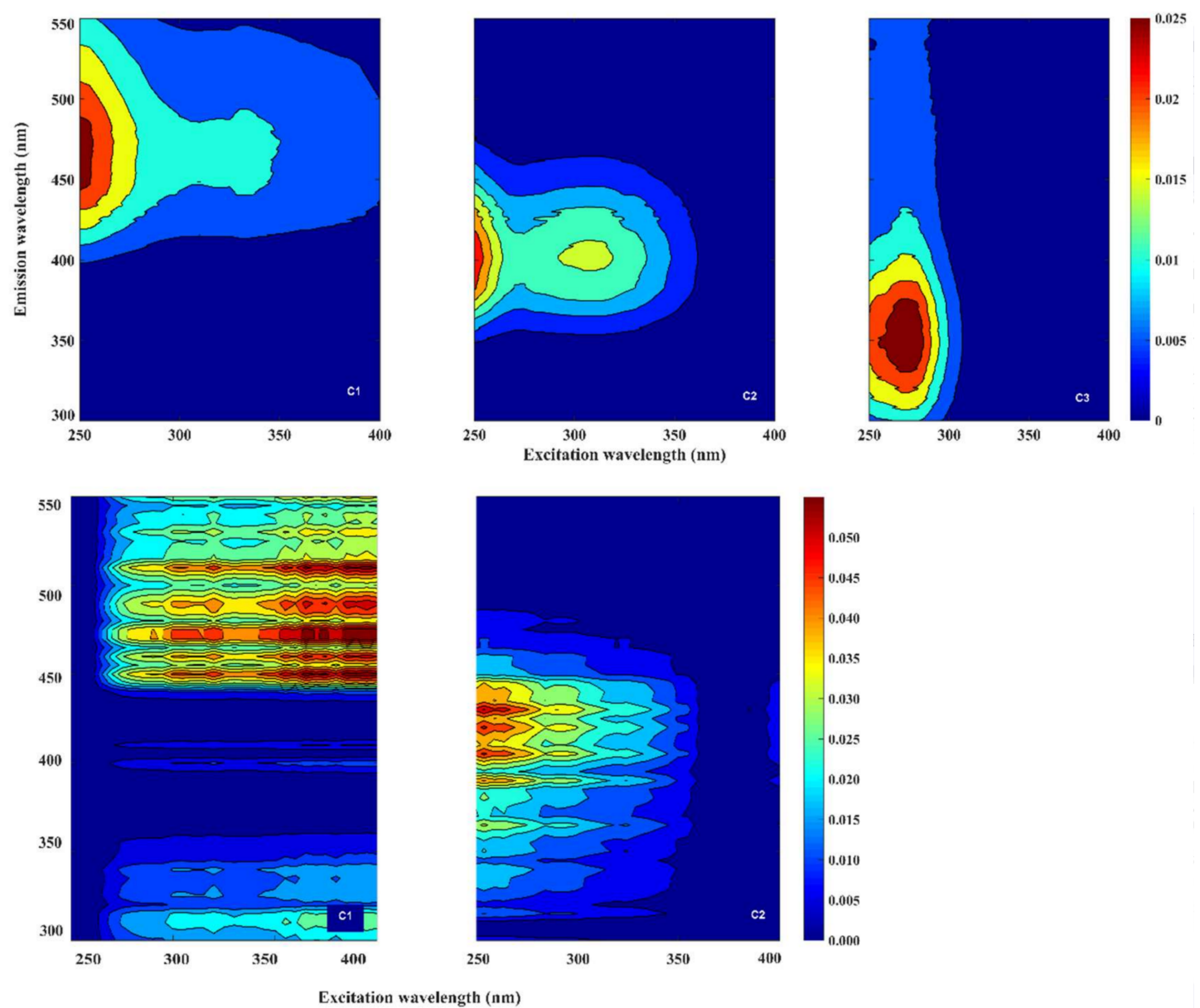

Figure 11. Top panel: PARAFAC-derived principal fluorescent components from lab-based EEM spectra from water samples at stations 11-15. From left to right: (C1) Terrestrial humic-like peaks $A_{C}$ and C; (C2) marine humic-like peaks $A_{M}$ and $M$; and (C3) protein-like Tryptophan peak T, all peaks denoted after Coble [29]. Color bar shows Raman units (RU). Bottom panel: PARAFAC derived principal fluorescent components from Kallemeter-based EEM spectra along the transect.

Table 2. Spectroscopic composition of the lab-based LS55 spectrofluorometer EEM spectra analyzed water samples in Trondheimsfjord. C1, C2, and C3 represent the intensity of PARAFAC components in Raman units.

\begin{tabular}{|c|c|c|c|c|c|c|}
\hline Sample Number & Station & Depth (m) & C1 (RU) & C2 (RU) & C3 (RU) & Date \\
\hline 1 & ST11 & 0.10 & 0.0364 & 0.0302 & 0.0238 & \multirow{4}{*}{20 July 2017} \\
\hline 2 & ST11 & 0.50 & 0.0349 & 0.0298 & 0.0243 & \\
\hline 3 & ST11 & 1.50 & 0.0354 & 0.0297 & 0.0283 & \\
\hline 4 & ST11 & 2.00 & 0.0331 & 0.0289 & 0.0304 & \\
\hline 5 & ST12 & 0.10 & 0.0252 & 0.0194 & 0.0162 & \multirow{4}{*}{22 July 2017} \\
\hline 6 & ST12 & 0.50 & 0.0231 & 0.0177 & 0.0106 & \\
\hline 7 & ST12 & 1.50 & 0.0226 & 0.0174 & 0.0127 & \\
\hline 8 & ST12 & 2.00 & 0.0227 & 0.0177 & 0.0130 & \\
\hline 9 & ST13 & 0.10 & 0.0355 & 0.0278 & 0.0214 & \multirow{4}{*}{23 July 2017} \\
\hline 10 & ST13 & 0.50 & 0.0355 & 0.0295 & 0.0287 & \\
\hline 11 & ST13 & 1.50 & 0.0323 & 0.0255 & 0.0173 & \\
\hline 12 & ST13 & 2.00 & 0.0322 & 0.0263 & 0.0191 & \\
\hline 13 & ST14 & 0.10 & 0.1772 & 0.1054 & 0.0363 & \multirow{4}{*}{24 July 2017} \\
\hline 14 & ST14 & 0.50 & 0.1745 & 0.1017 & 0.0247 & \\
\hline 15 & ST14 & 1.50 & 0.1763 & 0.1035 & 0.0248 & \\
\hline 16 & ST14 & 2.00 & 0.1749 & 0.1028 & 0.0263 & \\
\hline 17 & ST15 & 0.10 & 0.1471 & 0.0904 & 0.0378 & \multirow{4}{*}{25 July 2017} \\
\hline 18 & ST15 & 0.50 & 0.1493 & 0.0899 & 0.0233 & \\
\hline 19 & ST15 & 1.50 & 0.1543 & 0.0928 & 0.0241 & \\
\hline 20 & ST15 & 2.00 & 0.1530 & 0.0919 & 0.0232 & \\
\hline
\end{tabular}




\section{Discussion, Limitations, and Conclusions}

The main objective of this study was to present a novel in situ EEMS sensor system-the 'Kallemeter' - enabling full optical fingerprints in a submersible design. We presented the design of this system within the methods Section 2.1 and illustrated its application based on laboratory samples of diluted Suwannee River standards with $2.5 \mathrm{ppm}$ and $25 \mathrm{ppm}$, respectively. Fluorescence exhibited around EX: $240 \mathrm{~nm}$ and EM: $450 \mathrm{~nm}$ was corresponding to terrestrial humic-like peak C substances, as expected for Suwannee River standards, with increasing intensity and additional visible contributions extending to higher excitation wavelengths [50,51]. The assessment of the 'Kallemeter' EEMS sensor systems' signal-to-noise ratio (S/N) based on the Raman peak of water in a tap-water sample, provided an $\mathrm{S} / \mathrm{N}$ of 34 . Compared to commercially available laboratory spectrofluorometers that exhibit $\mathrm{S} / \mathrm{N}$ of 500 or higher the 'Kallemeter' is much more limited in resolving low signal intensities [39]. Part of this is based on the different optical components implemented, e.g., a fiber optic spectrometer compared to a monochromator plus photomultiplier setup for the LS55 spectrofluorometer, still considered as the gold-standard for high sensitivity applications. Also the choice of the excitation light was influenced by power- and heat-considerations and therefore restricted to $<10$ Watts, where other laboratory instruments like the Aqualog (Horiba, Kyoto, Japan) are equipped with up to 150 Watt Xenon flash lamps [52]. The strongest influence can be assumed from the application of fiber optics within the sensor, resulting in losses while coupling light in and out as well as transmitting it in the fiber. The use of fiber optics is a result of the compact design that a submersible housing requires-a potential redesign of the 'Kallemeter' will take this into account and try to partially avoid the use of optical fibers through direct light paths.

The field application of the 'Kallemeter' was realized in the moonpool of R/V Heincke on transect from Norwegian coastal waters into the Trondheimsfjord in July 2017. The system was successfully operated for five days in a fully submerged installation. EEM spectra derived from this application showed very low fluorescence intensities superimposed by noise components for all coastal sea measurements and the outer fjord area, while mid- and inner-fjord measurements exhibited clear broad signals of approximately EX: $250-300 \mathrm{~nm}$ and EM: $400-500 \mathrm{~nm}$. These observations are consistent with the spectral component intensities derived from laboratory UV-VIS spectrofluorometer (LS55, PerkinElmer, Waltham, MA, USA) measurements of surface water samples. With respect to components $\mathrm{C} 1$ and $\mathrm{C} 2$ derived from PARAFACS analysis these were ranging for the outer fjord between 0.02 and 0.04 Raman Units, while mid- and inner-fjord values ranged between 0.09 and $0.18 \mathrm{RU}$. The direct comparison of normalized EEM spectra from the lab-based spectrofluorometer and the 'Kallemeter' (Figure 10) illustrated both, the capability of the 'Kallemeter' to provide full EEM spectra if fluorescent organic matter concentrations are sufficiently high (stations 14 and 15), and the limitation to resolve low concentrations against the background noise as encountered at stations 12 and 13 in coastal waters. The latter is a result of the lower S/N and sensitivity, discussed above. The application of the 'Kallemeter' EEMS sensor system in its current form therefore seems to be limited towards areas with an increased amount of fluorescent organic matter, typically encountered in near coastal areas, estuaries and inland waters. Furthermore a study of the impact of noise or signal degradation applied on EEM spectra that serve as PARAFAC model input would be of interest to assess general limitations, however that is beyond the scope of this study.

The PARAFAC analysis of the Kallemeter-based EEM spectra enabled us to model two components, corresponding to terrestrial humic-like peaks $A_{C}$ and $C$, and marine humic-like peaks $\mathrm{A}_{\mathrm{M}}$ and $\mathrm{M}$. This was compared to a PARAFAC analysis of the LS55 spectrofluorometer EEM spectra from near surface water samples at the distinct stations that successfully validated three components. While lab-based components 1 and 2 resemble the in situ Kallemeter components (even though limited by high noise influence), the third component, namely the protein-like Tryptophan peak $\mathrm{T}$, could not be reproduced from the 'Kallemeter' data. Since peak T could be quantified in the laboratory measurements to an average intensity of 0.023 Raman units without any signal increase in the Trondheimsfjord, we consider this as a current limitation for the 'Kallemeter'. 
The ability to perform a PARAFAC analysis on automatically measured in situ EEM spectra is a major achievement and, to the best of our knowledge, the first of its kind. We encountered a couple of challenges to that end, that we provide here as current limitations but also avenues for future improvements. (A) Since we did not filter the water entering the measurement cell with $0.2 \mu \mathrm{m}$ (only applying $50 \mu \mathrm{m}$ to keep coarse material out) the signal observed is originating from dissolved, colloidal and particulate fractions of organic matter. For low amounts of particulate material this might not be a problem and indeed all in situ FDOM bulk fluorescence sensors (including the two used in this study for comparison) are also measuring unfiltered samples. However, for direct comparison with laboratory measured (filtered) FDOM EEM spectra this can be considered an obstacle. To overcome this, the installation of a filter unit at the inlet, containing an appropriate $0.2 \mu \mathrm{m}$ filter can be easily realized in future applications of the 'Kallemeter'. It can be speculated that part of the noisiness of the spectra and PARAFAC components can be associated to the influence of particulate material. (B) All EEM spectra need to be corrected for the inner filter effect (IFE). This typically requires a parallel measurement of the absorption spectra of the filtered water sample over the same wavelength range. The 'Kallemeter' itself is not suited to perform this absorption measurement, therefore we applied absorption spectra from water samples analyzed with a laboratory spectrophotometer. These were only available at the five stations investigated and not at the 48 measurement locations of the 'Kallemeter'. Assigning absorption spectra from samples that were gathered up to $24 \mathrm{~h}$ earlier or later is introducing uncertainties, even though we took care to respect the different oceanographic gradients encountered in the matching procedure. A much better way to account for this need of parallel absorption measurements will be to use automated in situ capable methods [53]. (C) Applying mirrors in the sample flow through cell, we increased the fluorescence signal intensity by a factor of 2.5, however IFE corrections applied to correct EEM spectra do not consider these and are therefore overcorrecting. Luciani et al. [54] showed how mirrors change the fluorescence signal and can be at the same time utilized to correct for IFE, if measurements with and without mirrors are performed on the same sample. This could be another methodological improvement to overcome constraints mentioned above.

Comparing the results from the bulk fluorescence signal of the 'Kallemeter' (calculated from the EEM spectra) with the flow through data from the commercially available FDOM sensors (a) inside the FerryBox (Cyclops-7-U, Turner Design, San Jose, CA, USA) and (b) the channel 11 from the recently developed matrix fluorescence sensor (MatrixFlu-UV, TriOS, Rastede, Germany), a good correspondence could be observed. The maximum exhibited on 23 July and the following decrease in the 'Kallemeter' fluorescence intensity (compare Figure 8) seems to be better reproduced by the Cyclops-7-U FDOM sensor. The corresponding MatrixFlu-UV channel is able to reproduce the same steep increase, however shows a signal reduction afterwards, not represented by the other methods applied in this study. As this study reports one of the first field datasets achieved with the MatrixFlu-UV sensor we cannot judge on this readings but see a clear need to investigate the sensors responses.

The MatrixFlu-UV sensor was investigated herein only with respect to one of its 12 channels representing a main spectral component in the investigated environment. It is therefore herein utilized as single-channel sensor and its further value in rapid quasi-EEM spectra measurements will be investigated in future works. Other multichannel approaches exist, with two [55] or three [56] combinations technically built up from single EX/EM combinations. A recent study of Nordic seas FDOM intensities [57] utilized a novel three-channel fluorometer (WETStar, Sea-Bird Scientific, Bellevue, WA, USA). This system excites the water sample in a flow-through cell with two LEDs at $280 \mathrm{~nm}$ and $310 \mathrm{~nm}$. Two detectors measure the emission at $350 \mathrm{~nm}$ and $450 \mathrm{~nm}$, allowing for a combination of channels in specific peak areas: peak $C$ (with EX/EM $310 \mathrm{~nm} / 450 \mathrm{~nm}$ ), peak $A_{C}$ (with EX/EM $280 \mathrm{~nm} / 450 \mathrm{~nm}$ ), and peak T (with EX/EM $280 \mathrm{~nm} / 350 \mathrm{~nm}$ ). All applications mentioned above underline the potential of multichannel FDOM measurements for specific components dominant in natural water bodies. The technological step from multichannel sensing to real excitation-emission matrix spectroscopy with high spectral resolution in both, the excitation and the emission sides, is huge, since it requires complete different technologies. An interim step with six (up to 12) distinct LED 
excitation wavelengths and emission spectra with 7.5-nm spacing (named 'LEDIF') was presented as part of a field-deployable optical system [58].

The 'Kallemeter' represents, to the best of our knowledge, the first submersible EEMS sensor system that performs full optical fingerprints. While the detection side is comparable to the LEDIF approach, using a fiber optical spectrometer, excitation was realized in our system by a Xenon flash lamp and an embedded controlled monochromator. This enabled us to achieve 10-nm steps in the excitation wavelengths selection (and finer steps are technically feasible); however, it also slows down the measurement process to approx. $30 \mathrm{~min}$ per individual sample. This is in the same order of magnitude as the LS55 (PerkinElmer, Waltham, MA, USA) UV-VIS laboratory spectrofluorometer used in this study. Faster laboratory systems exist nowadays (e.g., Aqualog, Horiba, Kyoto, Japan) that enable EEM spectra measurements below $5 \mathrm{~min}$ that require, however, further technical improvements (e.g., a TE cooled back-illuminated CCD fluorescence detector, and a high power Xenon flash lamp). Modern ocean observing strategies combine sensors with high spatiotemporal resolution but limited information depth with more sophisticated sensors, that provide a high depth of information but are limited in their spatial and temporal resolution [8]. The 'Kallemeter' is one of those highly sophisticated sensors and will likely, as others in that field [59,60], improve in its operational specifications, i.e., size, weight, and power. Multichannel fluorescence sensors for FDOM are already smaller, lightweight, and less power consuming. Their application on different autonomous platforms has been demonstrated $[17,55,58]$. Thus, they are the linkage towards resolving rapid changes and processes. An assessment of fluorescent organic matter in high spatiotemporal and spectral resolution is therefore technically feasible and likely to become standard in future biogeochemical ocean observatories.

Author Contributions: Conceptualization, O.Z.; Methodology, O.Z., N.R., O.D.F., M.L.M., and J.W.; Validation and analysis, O.Z., N.R., O.D.F., M.L.M., and J.W.; Field investigations, N.R, O.D.F., M.L.M., and J.W.; Project Administration, O.Z. and N.R.; Funding Acquisition and Resources, O.Z.; All authors contributed to the writing and revision process.

Funding: This research was partly funded by the Ministry of Science and Culture of Lower Saxony, Germany, as part of the 'Coastal Ocean Darkening' project, grant number [VWZN3175] and the 'EcoMol' graduate school. Development of the MatrixFlu-UV was partly funded by project NeXOS [grant agreement No. 614102] under the call FP7-OCEAN-2013.2 from the EU Commission as part of the 7th Framework Program, 'The Ocean of Tomorrow'. M.L.M. acknowledges SENACYT-IFARHU for the research scholarship (for Doctoral and Postdoctoral studies 2017/18, Program BIPD-2016). Additional funding was provided by EFRE-project 'MultiFlu', funded by NBank, Hannover, Germany [proposal number 85003576].

Acknowledgments: The authors are thankful to the master and crew onboard the R/V Heincke HE491 campaign. The cruise was supported by the Alfred Wegener Institute for Polar and Marine Research (AWI) and the German Federal Ministry of Education and Research (BMBF). Sincere thanks to Anna Friedrichs and Kathrin Dietrich for assistance in data collection and laboratory analysis of water samples. Additional thanks to Beke Tietjen for supporting the preparation of Figures 8 and 9 in their early form, Ursel Gerken for checking spelling and grammar, and Julian Beck for constructing the flow-through cuvette of the 'Kallemeter'. MatrixFlu-UV was built and provided by TriOS Mess- und Datentechnik GmbH, Rastede, Germany. FerryBox was kindly provided by Wilhelm Petersen, Institute of Coastal Research at the Helmholtz-Zentrum Geesthacht, Germany. Several components of the 'Kallemeter' were kindly provided by Axel Bochert and Jan Boelmann, University of Applied Science, Bremerhaven, Germany. The feedback from the participants of the WOMS 2018 workshop in Toulon (France), two anonymous reviewers, and Dariusz Stramski as editor is gratefully acknowledged.

Conflicts of Interest: The authors declare no conflict of interest. The funders had no role in the design of the study; in the collection, analyses, or interpretation of data; in the writing of the manuscript, and in the decision to publish the results. 


\section{Appendix A}

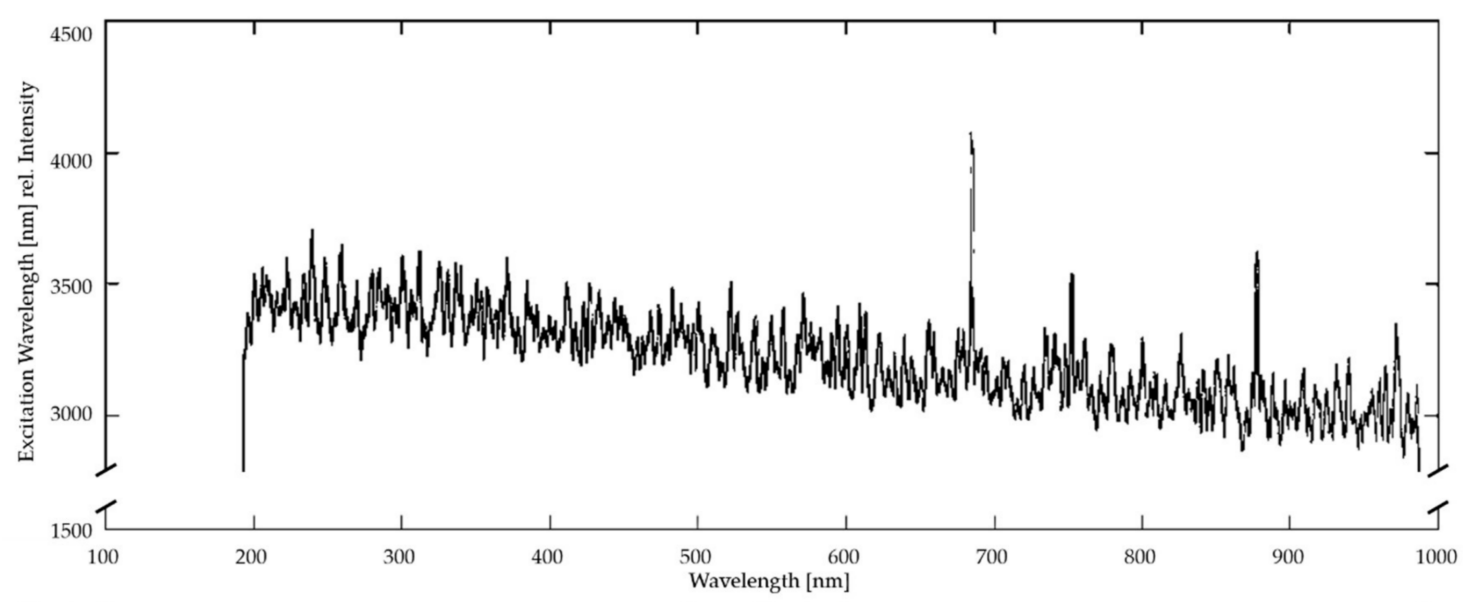

Figure A1. Dark counts of the 'Kallemeter' fluorescence detection spectrometer, measured by a long-term in situ test of 50 full EEM spectra (presented as an overlay) over a period of $116 \mathrm{~h}$ exhibiting a constant slight intensity gradient against the ordinate (wavelength).

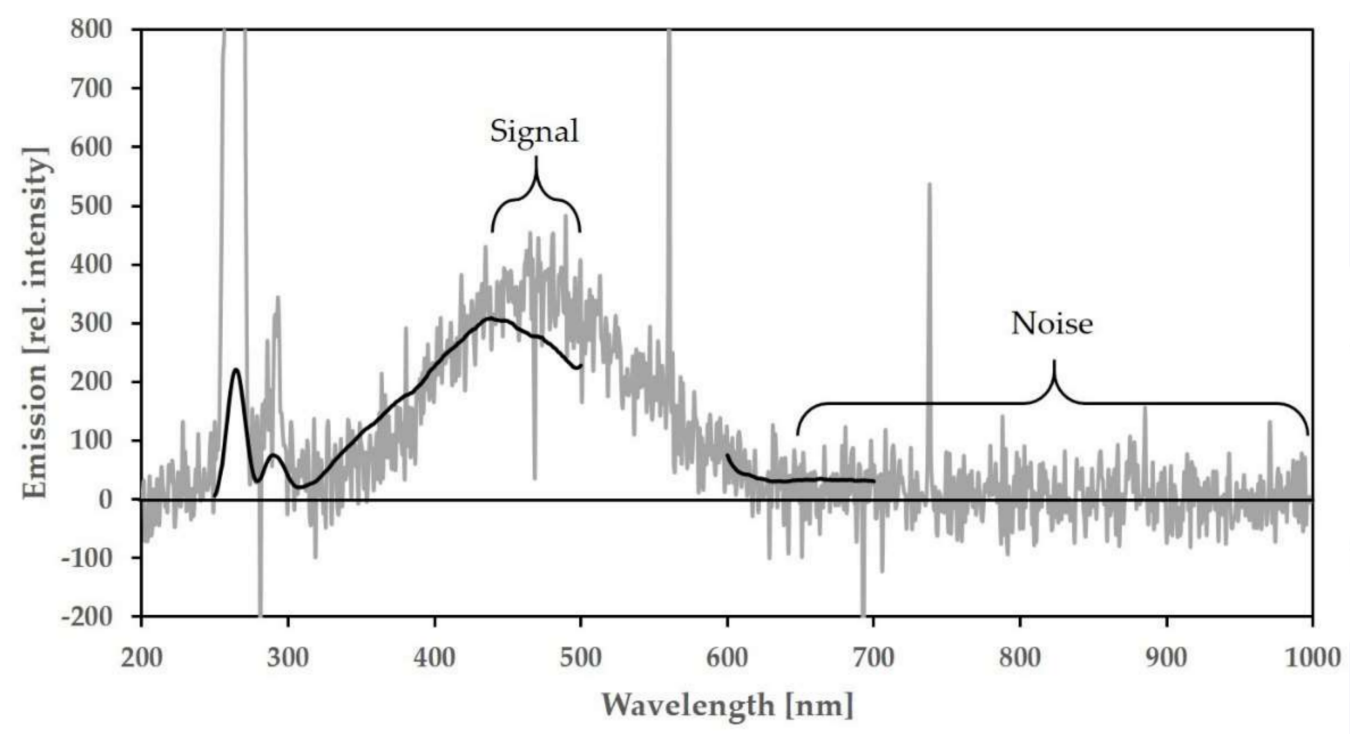

Figure A2. Signal to noise measurement of tap water with the 'Kallemeter' fluorescence detection spectrometer (grey line, integration time $300 \mathrm{~s}$ ), and the LS55 laboratory spectrofluorometer (black line, 2nd maxima masked), both excitation wavelengths are $260 \mathrm{~nm}$.

Table A1. Comparison of different mirror combinations within the measuring cell. Shown: Mirror on (opposite) excitation and emission side, maximum value of the fluorescence signal, signal-to-noise ratio (S/N). Measured: Compound 610 from Starna Scientific Ltd. (Ilford, UK), flash lamp frequency: $100 \mathrm{~Hz}$, excitation wavelength $440 \mathrm{~nm}$, integration time: $5 \mathrm{~s}$.

\begin{tabular}{cccc}
\hline Excitation Side & Emission Side & Max [counts] & S/N \\
\hline Concave & Concave & 678 & 156 \\
Concave & Planar & 571 & 157 \\
Planar & Concave & 650 & 187 \\
Planar & Planar & 570 & 145 \\
Absent & Absent & 346 & 94 \\
\hline
\end{tabular}



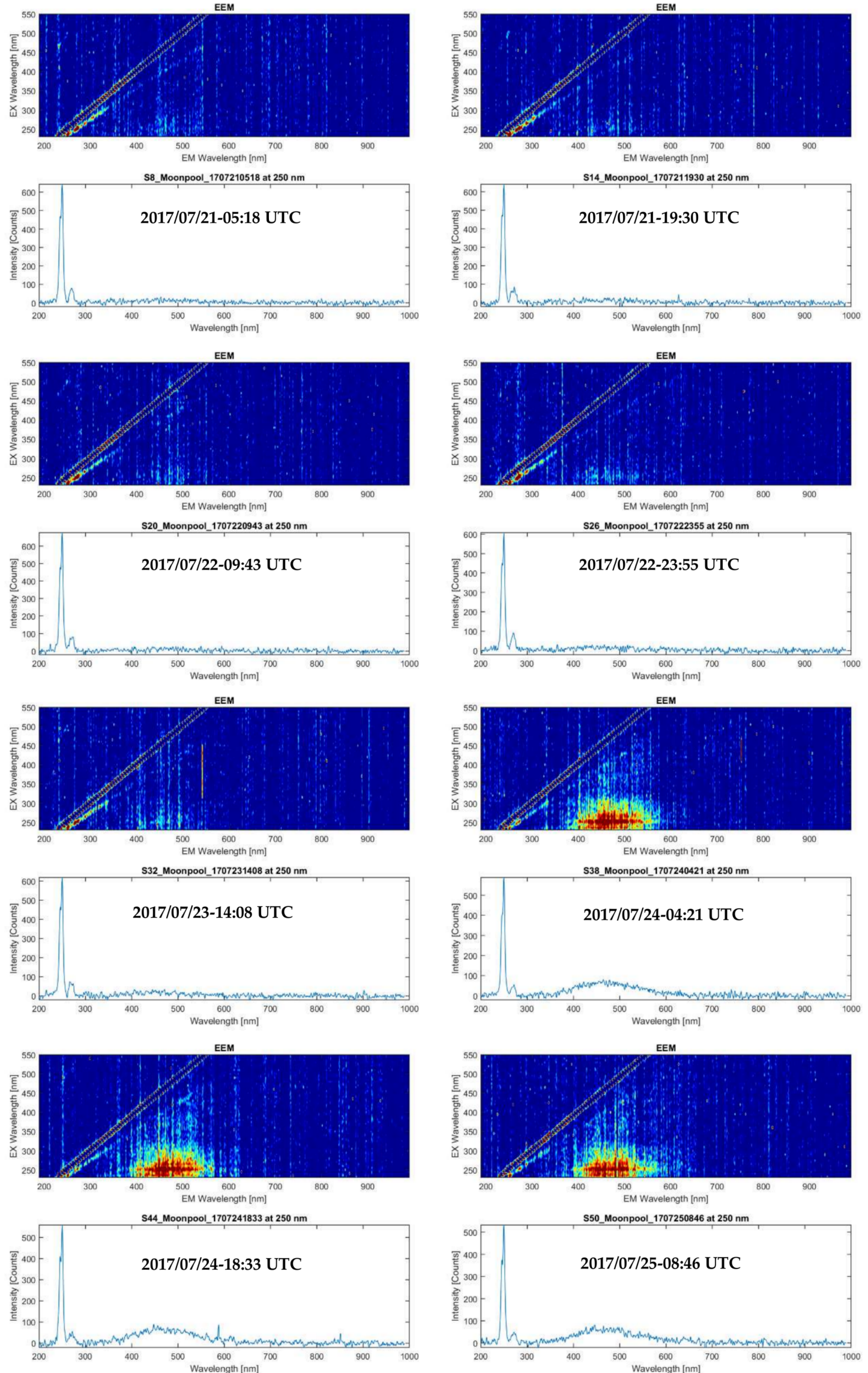

Figure A3. In situ underway measurements of EEM spectra, obtained from the moonpool of R/V Heincke (HE491) along transect from the coastal ocean into the Trondheimsfjord. 
Table A2. EEMS measurement parameters for intensity calibration procedures.

\begin{tabular}{cc}
\hline Parameter & Settings \\
\hline Excitation start & $200 \mathrm{~nm}$ \\
Scan steps & $5 \mathrm{~nm}$ \\
Excitation end & $450 \mathrm{~nm}$ \\
Dark correction & True \\
Dark noise multi scan & 20 \\
CM110 offset correction & None \\
CM110 slits & None \\
Integration time & $6 \mathrm{~s}$ \\
Scans to average & 10 \\
Box car & 0 \\
Trigger mode & 0 \\
Detector temperature & $-10{ }^{\circ} \mathrm{C}$ \\
PX-2 connect & Reference \\
Multiple strobe & On \\
Flash delay & 10 milliseconds \\
Warm-up & None \\
\hline
\end{tabular}

\section{References}

1. Mostofa, K.; Vione, D.; Mottaleb, M.; Yoshioka, T. (Eds.) Photobiogeochemistry of Organic Matter: Principles and Practices in Water Environments, 1st ed.; Springer: Heidelberg, Germany, 2013.

2. Dittmar, T. Reasons behind the long-term stability of marine organic matter. In The Biogeochemistry of Marine Dissolved Organic Matter, 2nd ed.; Hansell, D.A., Carlson, C.A., Eds.; Academic Press: Boston, MA, USA, 2015; pp. 369-388.

3. Ridgwell, A.; Arndt, S. Why Dissolved Organics Matter: DOC in Ancient Oceans and Past Climate Change. In The Biogeochemistry of Marine Dissolved Organic Matter, 2nd ed.; Hansell, D.A., Carlson, C.A., Eds.; Academic Press: Boston, MA, USA, 2015; pp. 1-20.

4. Watson, J.; Zielinski, O. Subsea Optics and Imaging; Woodhead Publishing Limited: Cambridge, UK, 2013.

5. Miranda, M.L.; Mustaffa, N.I.H.; Robinson, T.B.; Stolle, C.; Ribas-Ribas, M.; Wurl, O.; Zielinski, O. Influence of solar radiation on biogeochemical parameters and fluorescent dissolved organic matter (FDOM) in the sea surface microlayer of the southern coastal North Sea. Elem. Sci. Anth. 2018, 6, 15. [CrossRef]

6. Parlanti, E.; Wörz, K.; Geoffroy, L.; Lamotte, M. Dissolved organic matter fluorescence spectroscopy as a tool to estimate biological activity in a coastal zone submitted to anthropogenic inputs. Org. Geochem. 2000, 31, 1765-1781. [CrossRef]

7. Drozdowska, V.; Freda, W.; Baszanowska, E.; Rudz, K.; Darecki, M.; Heldt, J.T.; Toczek, H. Spectral properties of natural and oil polluted Baltic seawater-Results of measurements and modeling. Eur. Phys. J. Spec. Top. 2013, 222, 1-14. [CrossRef]

8. Zielinski, O.; Busch, J.A.; Cembella, A.D.; Daly, K.L.; Engelbrektsson, J.; Hannides, A.K.; Schmidt, H. Detecting marine hazardous substances and organisms: Sensors for pollutants, toxins, and pathogens. Ocean Sci. 2009, 5, 329-349. [CrossRef]

9. Friedrichs, A.; Ferdinand, O.; Miranda, M.L.; Zielinski, O. SmartFluo goes FDOM: Advancement of the DIY fluorometer approach towards UV excitation. In Proceedings of the OCEANS 2017, Aberdeen, UK, 19-22 June 2017.

10. Wymore, A.S.; Potter, J.; Rodríguez-Cardona, B.; McDowell, W.H. Using In-Situ Optical Sensors to Understand the Biogeochemistry of Dissolved Organic Matter Across a Stream Network. Water Resour. Res. 2018, 54, 2949-2958. [CrossRef]

11. Kalle, K. Zum Probleme der Meereswasserfarbe. Ann. Hydrol. Mar. Mitt. 1938, 66, 1-13.

12. Kirk, J.T.O. Light and Photosynthesis in Aquatic Ecosystems, 3rd ed.; Cambridge University Press: New York, NY, USA, 2011; p. 638.

13. Kowalczuk, P.; Ston-Egiert, J.; Cooper, W.J.; Whitehead, R.F.; Durako, M.J. Characterization of chromophoric dissolved organic matter (CDOM) in the Baltic Sea by excitation emission matrix fluorescence spectroscopy. Mar. Chem. 2005, 96, 273-292. [CrossRef] 
14. Coble, P. Marine optical biogeochemistry: The chemistry of ocean color. Chem. Rev. 2007, 107, 402-418. [CrossRef]

15. Para, J.; Coble, P.G.; Charrière, B.; Tedetti, M.; Fontana, C.; Sempéré, R. Fluorescense and absorption properties of chromophoric dissolved organic matter (CDOM) in coastal surface waters of the northwestern Mediterranean Sea, influence of the Rhône river. Biogeosciences 2010, 7, 4083-4103. [CrossRef]

16. Schüßler, U.; Kremling, K. A pumping system for underway sampling of dissolved and particulate trace elements in near-surface waters. Deep. Sea Res. Part I Oceanogr. Res. Pap. 1993, 40, 257-266. [CrossRef]

17. Moore, C.; Barnand, A.; Fietzek, P.; Lewis, M.; Sosik, H.; White, S.; Zielinski, O. Optical tools for ocean monitoring and research. Ocean Sci. 2009, 5, 661-684. [CrossRef]

18. Zaneveld, J.R.V.; Kitchen, J.C.; Moore, C.C. Scattering error correction of reflection-tube absorption meters. In Proceedings of the Ocean Optics XII, Bergen, Norway, 26 October 1994.

19. Tassan, S.; Ferrari, G.M. Variability of light absorption by aquatic particles in the near-infrared spectral region. Appl. Opt. 2003, 42, 4802-4810. [CrossRef] [PubMed]

20. Fry, E.S.; Kattawar, G.W.; Pope, R.M. Integrating cavity absorption meter. Appl. Opt. 1992, 31, $2055-2065$. [CrossRef] [PubMed]

21. Röttgers, R.; Doerffer, R. Measurements of optical absorption by chromophoric dissolved organic matter using a point-source integrating-cavity absorption meter. Limnol. Oceanogr. Methods 2007, 5, 126-135. [CrossRef]

22. Determann, S.; Lobbes, J.M.; Reuter, R.; Rullkötter, J. Ultraviolet fluorescence excitation and emission spectroscopy of marine algae and bacteria. Mar. Chem. 1998, 62, 137-156. [CrossRef]

23. Ferdinand, O.; Friedrichs, A.; Miranda, M.L.; Voß, D.; Zielinski, O. Next generation fluorescence sensor with multiple excitation and emission wavelengths-NeXOS MatrixFlu-UV. In Proceedings of the OCEANS 2017, Aberdeen, UK, 19-22 June 2017.

24. Fukuzaki, K.; Imai, I.; Fukushima, K.; Ishii, K.-I.; Sawayama, S.; Yoshioka, T. Fluorescent characteristics of dissolved organic matter produced by bloom-forming coastal phytoplankton. J. Plankton Res. 2014, 36, 685-694. [CrossRef]

25. Lee, E.; Yoo, G.; Jeong, Y.; Kim, K.; Park, J.; Oh, N. Comparison of UV-VIS and FDOM sensors for in situ monitoring of stream DOC concentrations. Biogeosciences 2015, 12, 3109-3118. [CrossRef]

26. Mustaffa, N.I.H.; Ribas-Ribas, M.; Wurl, O. High-resolution variability of the enrichment of fluorescence dissolved organic carbon in the sea surface microlayer of an upwelling region. Elem. Sci. Anth. 2017, 5, 52. [CrossRef]

27. Kowalczuk, P.; Tilstone, G.H.; Zabłocka, M.; Röttgers, R.; Thomas, R. Composition of dissolved organic matter along an Atlantic Meridional Transect from fluorescence spectroscopy and Parallel Factor Analysis. Mar. Chem. 2013, 157, 170-184. [CrossRef]

28. Miranda, M.L.; Trozjuck, A.; Voss, D.; Gassmann, S.; Zielinski, O. Spectroscopic evidence of anthropogenic compounds extraction from polymers by fluorescent dissolved organic matter in natural water. J. Eur. Opt. Soc. Rapid Publ. 2016, 11, 16014. [CrossRef]

29. Coble, P. Characterization of marine and terrestrial DOM in seawater using excitation-emission matrix spectroscopy. Mar. Chem. 1996, 51, 325-346. [CrossRef]

30. Zsolnay, A.; Baigar, E.; Jimenez, M.; Steinweg, B.; Saccomandi, F. Differentiating with fluorescence spectroscopy the sources of dissolved organic matter in soils subjected to drying. Chemosphere 1999, 38, 45-50. [CrossRef]

31. Huguet, A.; Vacher, L.; Relexans, S.; Saubusse, S.; Froidefond, J.M.; Parlanti, E. Properties of fluorescent dissolved organic matter in the Gironde Estuary. Org. Geochem. 2009, 40, 706-719. [CrossRef]

32. Drozdowska, V.; Kowalczuk, P.; Jozefowicz, M. Spectrofluorometric characteristics of fluorescent dissolved organic matter in a surface microlayer in the Southern Baltic coastal waters. J. Eur. Opt. Soc. Rapid Publ. 2015, 10, 15050. [CrossRef]

33. Murphy, K.R.; Stedmon, C.A.; Graeber, D.; Bro, R. Fluorescense spectroscopy and multi-way techniques. Parafac. Anal. Methods 2013, 5, 6557-6566. [CrossRef]

34. Bro, R. PARAFAC. Tutorial and applications. Chemom. Intell. Lab. Syst. 1997, 38, 149-171. [CrossRef]

35. Delauney, L.; Compere, C.; Lehaitre, M. Biofouling protection for marine environmental sensors. Ocean Sci. 2010, 6, 503-511. [CrossRef] 
36. Coble, P.; Spencer, G.; Baker, A.; Darren, M. (Eds.) Aquatic Organic Matter Fluorescence; Cambridge University Press: Cambridge, UK, 2014.

37. Ocean Optics. PX-2 Pulsed Xenon Lamp Stability; Engineering Note 110-00000-000-04-0704; Ocean Optics: Largo, FL, USA, 2002.

38. Manov, D.V.; Chang, G.C.; Dickey, T.D. Methods for reducing biofouling of morred optical sensors. J. Atmos. Ocean. Technol. 2004, 21, 958-968. [CrossRef]

39. Lawaetz, A.J.; Stedmon, C.A. Fluorescence Intensity Calibration Using the Raman Scatter Peak of Water. Appl. Spectrosc. 2009, 63, 936-940. [CrossRef] [PubMed]

40. Heibati, M.; Stedmon, C.A.; Stenroth, K.; Rauch, S.; Toljander, J.; Säve-Söderbergh, M.; Murphy, K.R. Assessment of drinking water quality at the tap using fluorescence spectroscopy. Water Res. 2017, 125, 1-10. [CrossRef] [PubMed]

41. Perdue, E.M. Standard and Reference Samples of Humic Acids, Fulvic Acids, and Natural Organic Matter from the Suwannee River, Georgia: Thirty Years of Isolation and Characterization. In Functions of Natural Organic Matter in Changing Environment; Springer: Heidelberg, Germany, 2013.

42. Stedmon, C.A.; Markager, S. Resolving the variability in dissolved organic matter fluorescence in a temperate estuary and its catchment using PARAFAC analysis. Limnol. Oceanogr. 2005, 50, 686-697. [CrossRef]

43. Pearlman, J.; Zielinski, O. A new generation of optical systems for ocean monitoring-Matrix fluorescence for multifunctional ocean sensing. Sea Technol. 2017, 2, 30-33.

44. Delory, E.; Castro, A.; Waldmann, C.; Rolin, J.F.; Woerther, P.; Gille, J.; Del Rio, J.; Zielinski, O.; Golmen, L.; Hareide, N.R.; et al. NeXOS development plans in ocean optics, acoustics and observing systems interoperability. In Proceedings of the 2014 IEEE Sensor Systems for a Changing Ocean (SSCO), Brest, France, 13-17 October 2014.

45. Coble, P. Colored dissolved organic matter in seawater. In Subsea Optics and Imaging; Watson, J., Zielinski, O., Eds.; Woodhead: Cambridge, UK, 2013; pp. 98-118.

46. Stedmon, C.A.; Markager, S.; Bro, R. Tracing dissolved organic matter in aquatic environments using a new approach to fluorescence spectroscopy. Mar. Chem. 2003, 82, 239-254. [CrossRef]

47. Turner Designs. Optical Specification Guide for Cyclops Submersible Sensors; Engineering Note 998-2181 Rev. U; Turner Designs: San Jose, CA, USA, 2018.

48. Jacobson, P. Physical Oceanography of the Trondheimsfjord. Geophys. Astrophys. Fluid Dyn. 1983, $26,3-26$. [CrossRef]

49. Mascarenhas, V.J.; Voß, D.; Wollschlaeger, J.; Zielinski, O. Fjord light regime: Bio-optical variability, absorption budget, and hyperspectral light availability in Sognefjord and Trondheimsfjord, Norway. J. Geophys. Res. Oceans 2017, 122, 3828-3847. [CrossRef]

50. Carstea, E. Fluorescence Spectroscopy as a Potential Tool for In-Situ Monitoring of Dissolved Organic Matter in Surface Water Systems. In Water Pollution; InTech: London, UK, 2012; pp. 47-68.

51. Goldberg, M.; Wiener, E. Fluorescence Measurements of the Volume, Shape, and Fluorophore Composition of Fulvic Acid from the Suwannee River. In Humic Substances in the Suwannee River, Georgia; Interactions, Properties, and Proposed Structures; Averett, R.C., Leenheer, A., McKnight, M., Thorn, A., Eds.; United States Geological Survey Water-Supply Paper 2373; USGS: Reston, VA, USA, 1994; pp. 100-113.

52. Gilmore, A.M.; Cohen, S.M. Analysis of chromophoric dissolved organic matter in water by EEMs with HORIBA-Jobin Yvon fluorescence instrument called "Aqualog". Readout 2013, 41, 19-24.

53. Wollschläger, J.; Voß, D.; Zielinski, O.; Petersen, W. In situ observations of biological and environmental parameters by means of optics-development of next-generation ocean sensors with special focus on an integrating cavity approach. IEEE J. Ocean. Eng. 2016, 41, 753-762. [CrossRef]

54. Luciani, X.; Redon, R.; Mounier, S. How to correct inner filter effects altering 3D fluorescence spectra by using a mirrored cell. Chemom. Intell. Lab. Syst. 2013, 126, 91-99. [CrossRef]

55. Cyr, F.; Tedetti, M.; Besson, F.; Beguery, L.; Doglioli, A.M.; Petrenko, A.A.; Goutx, M. A New Glider-Compatible Optical Sensor for Dissolved Organic Matter Measurements: Test Case from the NW Mediterranean Sea. Front. Mar. Sci. 2017, 4, 89. [CrossRef]

56. Mayerfeld, P. Fluorometers: Integration experiences with unmanned vehicles. In Proceedings of the OCEANS 2017, Anchorage, AK, USA, 18-21 September 2017. 
57. Makarewicz, A.; Kowalczuk, P.; Sagan, S.; Granskog, M.A.; Pavlov, A.K.; Zdun, A.; Borzycka, K.; Zabłocka, M. Characteristics of chromophoric and fluorescent dissolved organic matter in the Nordic Seas. Ocean Sci. 2018, 14, 543-562. [CrossRef]

58. Ng, C.L.; Senft-Grupp, S.; Hemond, H.F. A multi-platform optical sensor for in situ sensing of water chemistry. Limnol. Oceanogr. Methods 2012, 10, 978-990. [CrossRef]

59. Herfort, L.; Seaton, C.; Wilkin, M.; Roman, B.; Preston, C.M.; Marin, R., III; Seitz, K.; Smith, M.W.; Haynes, V.; Scholin, C.A.; et al. Use of continuous, real-time observations and model simulations to achieve autonomous, adaptive sampling of microbial processes with a robotic sampler. Limnol. Oceanogr. Methods 2016, 14, 50-67. [CrossRef]

60. Olson, R.; Shalapyonok, A.; Kalb, D.; Graves, S.; Sosik, H. Imaging FlowCytobot modified for high throughput by in-line acoustic focusing of sample particles. Limnol. Oceanogr. Methods 2017, 15, 867-874. [CrossRef]

(c)

(C) 2018 by the authors. Licensee MDPI, Basel, Switzerland. This article is an open access article distributed under the terms and conditions of the Creative Commons Attribution (CC BY) license (http://creativecommons.org/licenses/by/4.0/). 